\title{
Infrared Spectra of High Polymers. II. Polyethylene*
}

\author{
S. Krimi, C. Y. Liang, and G. B. B. M. Sutherland \\ Harrison M. Randall Laboratory of Physics, University of Michigan, Ann Arbor, Michigan
}

(Received October 27, 1955)

\begin{abstract}
The infrared spectrum of polyethylene has been obtained between about $3000 \mathrm{~cm}^{-1}$ and $70 \mathrm{~cm}^{-1}$, polarization measurements on oriented specimens having been obtained to about $350 \mathrm{~cm}^{-1}$. Assignments of the fundamentals are made with the help of a group theory analysis. The assignment of the controversial $\mathrm{CH}_{2}$ wagging mode is discussed in detail and especially in terms of new evidence from the spectra of $n$-paraffins, both as single crystals and as polycrystalline aggregates. It is shown that this mode is to be assigned to a weak band at $1369 \mathrm{~cm}^{-1}$. A satisfactory determination of the bands which arise from $\mathrm{CH}_{3}$ groups is also made possible by a study of the paraffin spectra. The splitting of bands in the spectrum is conclusively shown to arise from interactions between molecules in the crystalline phase. The nature of this interaction is discussed in terms of recent theories.
\end{abstract}

\section{INTRODUCTION}

$\mathrm{T}$ HE preceding paper in this series ${ }^{1}$ dealt with the general theory which can be applied to the interpretation of the infrared spectra of high polymers. This paper considers in detail the interpretation of the infrared spectrum of polyethylene. It is natural to begin with this polymer since it is structurally the simplest and has a relatively uncomplicated spectrum. In spite of these helpful features, however, only a partial interpretation has been achieved in the past, primarily as a result of lack of pertinent experimental data on $n$-paraffins and of a rigorous theoretical discussion. We have obtained new experimental data on polyethylene which include (a) an extension of the spectrum from $700 \mathrm{~cm}^{-1}$ to $70 \mathrm{~cm}^{-1}$, (b) a study of the spectra of crystalline $n$-paraffins and the changes in spectrum resulting from a change in state, and (c) an examination of the spectrum of a fully deuterated $n$-paraffin. With the help of these added data, and the utilization of group theory methods in the analysis, we have been able to achieve a satisfactory interpretation of the spectrum of polyethylene.

\section{EXPERIMENTAL}

The spectroscopic techniques used in obtaining the spectra have been described already. The samples of polyethylene used in this investigation were unoriented sheets obtained from E. I. du Pont de Nemours and Company. Orientation was produced by cold-drawing as fully as possible. It is known that this treatment produces uniaxial orientation of the crystallites, the crystal $c$-axis, or chain axis, becoming parallel to the stretching direction. ${ }^{2,3}$ In addition, a partial orientation of the chains in the amorphous regions occurs, such that they too are parallel to the stretching direction. ${ }^{4}$ The samples of pure $n$-paraffins were made available

* Presented in part at the American Physical Society Meeting, Ann Arbor, March, 1954.

${ }^{1}$ Liang, Krimm, and Sutherland, J. Chem. Phys. 25, 543 (1956).

${ }^{2}$ C. W. Bunn, Trans. Faraday Soc. 35, 482 (1939).

${ }^{3}$ C. W. Bunn and T. C. Alcock, Trans. Faraday Soc. 41, 317 (1945).

is. Krimm, J. Chem. Phys. 22, 567 (1954). to us by Carbide and Carbon Chemicals Company $\left(\mathrm{C}_{36} \mathrm{H}_{74}\right.$ and $\left.\mathrm{C}_{64} \mathrm{H}_{130}\right)$ and the Shell Development Company $\left(\mathrm{C}_{27} \mathrm{H}_{36}, \mathrm{C}_{28} \mathrm{H}_{58}, \mathrm{C}_{29} \mathrm{H}_{60}, \mathrm{C}_{30} \mathrm{H}_{62}\right)$. The solid state spectra of these hydrocarbons were obtained by melting a suitable thickness onto a rocksalt plate. A heated microcell was used to examine the spectra in the melted state. Some of these paraffins were studied as single crystals, which were grown by evaporation of a solution of the paraffin in a suitable solvent. The orientation and perfection of the crystals were determined from x-ray diffraction photographs. The fully deuterated $n$-paraffin was purchased from Tracerlab. It does not consist of a single species but closely approximates $\mathrm{C}_{100} \mathrm{D}_{202}$ in composition. Its spectrum was obtained as a thin film melted onto a rocksalt plate.

\section{THE INFRARED SPECTRUM OF POLYETHYLENE}

The infrared spectrum of oriented polyethylene between 700 and $100 \mathrm{~cm}^{-1}$ has been reported on. ${ }^{5}$ We have recently extended the spectrum to about $70 \mathrm{~cm}^{-1}$, and such a spectrum is shown in Fig. 1. Various specimen thicknesses (indicated on the diagram) had to be used in order to obtain all of the bands under optimum conditions. The dichroism was measured only at frequencies above about $350 \mathrm{~cm}^{-1}$. The polarization is indicated on the spectrum, the solid curve representing radiation polarized with the electric vector perpendicular to the stretching direction and the dashed curve radiation polarized parallel to the stretching direction. The broad band at about $550 \mathrm{~cm}^{-1}$ was found to be unpolarized. Below about $400 \mathrm{~cm}^{-1}$ interference fringes appeared in the spectrum (corresponding to a refractive index of about 1.46) and somewhat obscured the exact transmission curve. The best value, obtained from samples in which the interference was reduced, is shown by the dotted curve below $400 \mathrm{~cm}^{-1}$. The frequencies of the observed band maxima, their approximate relative intensities, and their dichroism with respect to the direction of stretch are given in Table I. Also shown there are the assignments, which will be discussed later.

${ }^{5}$ S. Krimm and G. B. B. M. Sutherland, Symposium on Molecular Structure and Spectroscopy, Columbus, Ohio, June, 1952. 


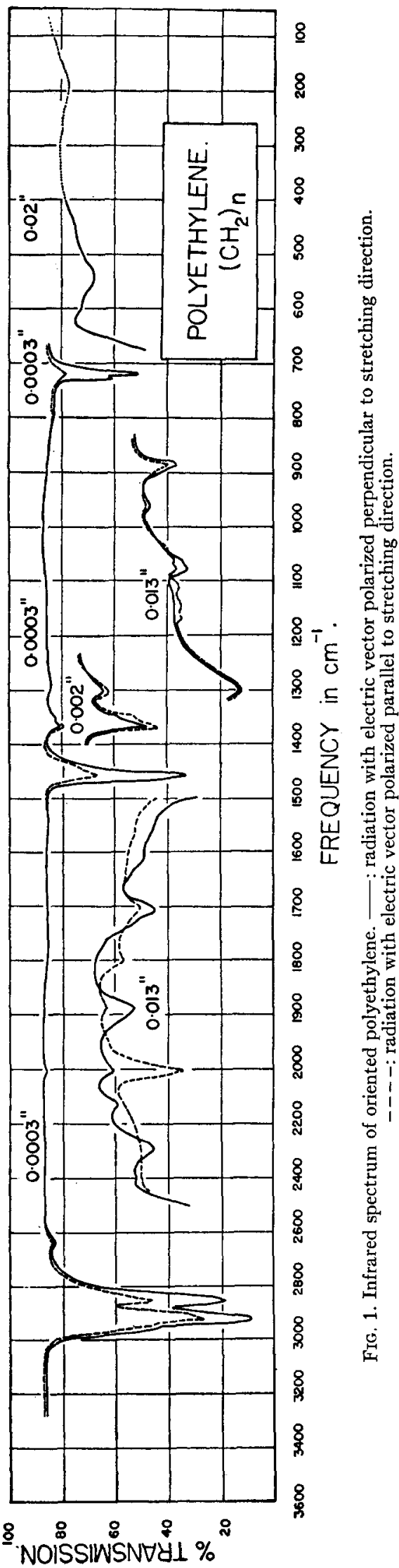

The observed bands in the prism region (3200-700 $\mathrm{cm}^{-1}$ ) are in satisfactory agreement with the results obtained by previous workers ${ }^{6-8}$ the difference in band maxima never being greater than about $2 \mathrm{~cm}^{-1}$. The spectrum has also been examined by means of a grating spectrometer in the $2900 \mathrm{~cm}^{-1}$ and $1400 \mathrm{~cm}^{-1}$ regions. ${ }^{9}$ The following differences have been observed. The grating spectra show a weak shoulder at $2875 \mathrm{~cm}^{-1}$ which is not resolved in the prism spectra. They also indicate that the band which we have observed at $1460 \mathrm{~cm}^{-1}$ is composite, with a strong component at $1463 \mathrm{~cm}^{-1}$, a weaker one at $1473 \mathrm{~cm}^{-1}$, and a weak shoulder at $1456 \mathrm{~cm}^{-1}$. Our value is apparently the mean of these components, which are not resolved in the prism spectra. The three maxima observed by us at $1375 \mathrm{~cm}^{-1}, 1369 \mathrm{~cm}^{-1}$, and $1353 \mathrm{~cm}^{-1}$ are reported at $1378 \mathrm{~cm}^{-1}, 1370 \mathrm{~cm}^{-1}$, and $1353 \mathrm{~cm}^{-1}$, respectively. As a result of our grating spectrometer observations in the frequency region below $700 \mathrm{~cm}^{-1}$, we have found ${ }^{5}$ two new bands at $600 \mathrm{~cm}^{-1}$ (with a weak shoulder at $543 \mathrm{~cm}^{-1}$ ) and at about $200 \mathrm{~cm}^{-1}$. The $600 \mathrm{~cm}^{-1}$ band has also been observed since ${ }^{9,10}$ in prism spectra. Some of the other weaker bands are somewhat variable in their appearance in spectra obtained by different observers. This is due to the fact that they arise from impurities and thus vary from specimen to specimen, as for example the bands at $1710 \mathrm{~cm}^{-1}$ (associated with carbonyl groups ${ }^{11}$ ) and in the $900 \mathrm{~cm}^{-1}$ to $1000 \mathrm{~cm}^{-1}$ region (arising from unsaturated carbon-carbon bonds ${ }^{12}$ ). The spectrum in Fig. 1 may be considered as representative of that of polyethylene.

\section{INTERPRETATION OF THE SPECTRUM}

\section{A. Predicted Spectrum of Isolated Polyethylene Chain}

Before considering the interpretation of the spectrum of polyethylene, it is necessary to know the structure of the molecule. Although polyethylene may be considered to a first approximation as an infinite chain of $\mathrm{CH}_{2}$ groups, the chains are found in essentially two different configurations. In the crystalline regions, whose structure is known from $x$-ray diffraction studies, ${ }^{2}$ the chain is found in the planar zig-zag configuration. In the amorphous, regions, which can constitute up to half of the specimen, ${ }^{13}$ the chain configuration is an essentially random one restricted only by the conservation of bond angles and distances. ${ }^{14}$ The random con-

${ }^{6}$ J. J. Fox and A. E. Martin, Proc. Roy. Soc. (London) A175, $208(1940)$.

${ }^{7} \mathrm{H}$. W. Thompson and P. Torkington, Proc. Roy. Soc. (London) A184, 3 (1945).

${ }^{8}$ Elliott, Ambrose, and Temple, J. Chem. Phys. 16, 877 (1948).

${ }^{9}$ Rugg, Smith, and Wartman, J. Polymer Sci. 11, 1 (1953).

${ }^{10}$ E. Borello and C. Mussa, J. Polymer Sci. 13, 402 (1954).

11 Rugg, Smith, and Bacon, J. Polymer Sci. 13, 535 (1954).

12 Cross, Richards, and Willis, Discussions Faraday Soc. 9, 235 (1950).

${ }_{13}$ S. Krimm and A. V. Tobolsky, J. Polymer Sci. 7, 57 (1951).

${ }^{14}$ A. Charlesby, J. Polymer Sci. 10, 201 (1953). 
figuration in the amorphous regions becomes a partially oriented one when the sample is stretched. ${ }^{4} \mathrm{It}$ is thus very important to keep in mind that the usual spectrum of polyethylene represents a superposition of the spectra of two different types of chain configurations. The spectra of these two components are not identical, and failure to recognize this has led to erroneous assignments.

The spectrum of the polymer in the amorphous regions is not subject to any selection rules, ${ }^{1}$ whereas the high symmetry of the chain configuration in the crystalline region does give rise to selection rules in its spectrum. We will now consider the spectrum to be expected from the crystalline polyethylene. In particular, although the complete analysis (to be discussed later) requires consideration of the two molecules in the unit cell, the essential features of the spectrum can be derived from a single isolated molecule, and we discuss this problem first. As pointed out previously, ${ }^{1}$ the transition to the full unit cell can generally only have the effect of splitting the frequencies of the isolated molecule, usually by a small amount, and, depending on the symmetry in the space lattice, possibly changing some selection rules.

The repeating unit in a single infinitely long polyethylene chain consists of two $\mathrm{CH}_{2}$ groups. This unit is shown in Fig. 2 between wavy vertical lines. The symmetry elements which reproduce the repeating unit, a translation along the chain being considered as identity, are also shown in the figure. The screw axis is denoted by $C^{s}$ and the glide plane by $\sigma_{g}$. This set of symmetry elements defines a factor group, in terms of which the spectrum can be analyzed. ${ }^{15}$ This mathematical analysis has the physical implication that only those fundamental modes can be active in infrared or Raman spectra in which corresponding atoms in all unit cells move in phase. The factor group for a single polyethylene chain is found $d^{15,16}$ to be isomorphous with the point group $D_{2 h}$, and the character table for this point group is given in Table II. Also shown in Table II, (and derived from the factor group analysis) are the number of normal modes and the selection rules in the infrared and Raman spectra under each symmetry species. The number of normal modes, $n_{i}$, under any given symmetry species are also shown as they are distributed among pure translations, $T$, translatory type vibrations, $T^{\prime}$, rotatory type vibrations, $R^{\prime}$, (which includes a pure rotation $R_{x}$ ) and internal vibrations, $n_{i}{ }^{\prime}$. The table shows that of the $3 \times 6-4=14$ normal modes of the repeating unit of polyethylene, 5 will give rise to infrared active fundamental frequencies, 8 to Raman active fundamentals, and one will be inactive in both infrared and Raman spectra. The frequencies which are active in infrared are inactive in Raman spectra, and vice versa; that is, the mutual exclusion rule holds.

${ }^{15} \mathrm{~S}$. Bhagavantam and T. Venkatarayudu, The Theory of Groups and Its Application to Physical Problems (Andhra University, Waltair, India, 1951).

${ }^{16}$ M. C. Tobin, J. Chem. Phys. 23, 891 (1955).

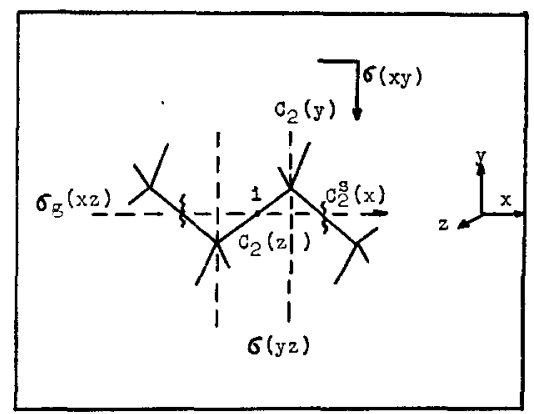

FIG. 2. Portion of polyethylene chain with associated symmetry elements; $C_{2}-$ diad, $C_{2}{ }^{8}-$ screw diad, $\sigma-$ mirror plane, $\sigma_{\sigma}-$ glide plane, $i$-center of inversion. The small $V$ 's denote $\mathrm{CH}_{2}$ groups, the $\mathrm{C}$ being at the apex and the H's at the extremities of the $V$.

Furthermore, the polarization of a given infrared fundamental can be determined from the translation belonging to that symmetry species. Thus, modes under species $B_{1 u}$ and $B_{2 u}$ are expected to show perpendicular polarization with respect to the chain axis, and modes under $B_{3 u}$, parallel polarization. The factor group analysis is therefore immediately useful in predicting the number and type of normal modes which can be infrared active.

We can carry this information one step further and deduce the approximate physical nature of the normal vibrations from the symmetry properties of the various

TABLE I. Infrared spectrum and assignments for polyethylene.

\begin{tabular}{|c|c|c|c|}
\hline $\begin{array}{l}\text { Frequency, } \\
\mathrm{cm}^{-1}\end{array}$ & Intensity & $\begin{array}{c}\text { Polariza- } \\
\text { tion }\end{array}$ & Assignment ${ }^{8}$ \\
\hline 2959 & $w(\mathrm{sh})$ & $\cdots$ & $\nu_{a}\left(\mathrm{CH}_{3}\right)$ \\
\hline 2925 & vs & $\sigma$ & $\nu_{a}\left(\mathrm{CH}_{2}\right)^{\mathbf{c}}$ \\
\hline $2874^{b}$ & vw & $\cdots$ & $\nu_{s}\left(\mathrm{CH}_{3}\right)$ \\
\hline 2853 & $\mathrm{~s}$ & $\sigma$ & $\nu_{s}\left(\mathrm{CH}_{2}\right)^{\mathrm{d}}$ \\
\hline 2640 & $w$ & $\sigma$ & \\
\hline 2295 & vw & $\sigma$ & \\
\hline 2130 & vvw & $\sigma$ & \\
\hline 2010 & $\mathrm{vw}$ & $\pi$ & $1303+721=2024$ \\
\hline 1890 & $\mathrm{vw}$ & $\sigma$ & \\
\hline 1805 & vvw & $\pi$ & \\
\hline 1710 & vw & $\sigma$ & \\
\hline $1470^{\mathrm{b}}$ & $\mathbf{s}$ & $\sigma\}$ & \\
\hline 1460 & $\mathrm{~s}$ & $\sigma\}$ & $\delta\left(\mathrm{CH}_{2}\right)$ \\
\hline $1456^{\mathrm{b}}$ & vw & $\cdots$ & $\delta_{a}\left(\mathrm{CH}_{3}\right)$ \\
\hline 1375 & $\mathrm{~m}$ & $\pi(?)$ & $\delta_{s}\left(\mathrm{CH}_{3}\right)$ \\
\hline 1369 & $w$ & $\pi$ & $\gamma_{w}\left(\mathrm{CH}_{2}\right)$ \\
\hline 1353 & $\mathrm{w}$ & $\pi$ & $\gamma_{w}\left(\mathrm{CH}_{2}\right)$ amorphous regions \\
\hline 1303 & $w$ & $\pi$ & $\gamma_{w}\left(\mathrm{CH}_{2}\right)$ amorphous regions \\
\hline 1170 & vvw & $\pi$ & \\
\hline 1150 & vvw & $\pi$ & \\
\hline 1110 & vvw & $\pi$ & \\
\hline 1080 & vw & $\sigma$ & $\nu(\mathrm{CC})$ amorphous regions \\
\hline 1065 & $\mathrm{vw}(\mathrm{sh})$ & $\sigma$ & $\nu(\mathrm{CC})$ \\
\hline 965 & vvw & $\cdots$ & \\
\hline 888 & vw & $\sigma$ & $\gamma_{r}\left(\mathrm{CH}_{3}\right)$ \\
\hline 731 & $\mathrm{~m}$ & $\sigma\}$ & \\
\hline 721 & $\mathbf{s}$ & $\sigma\}$ & $\gamma_{r}\left(\mathrm{CH}_{2}\right)$ \\
\hline 600 & vw & $\cdots$ & \\
\hline 543 & $\mathbf{w}$ & $\cdots$ & \\
\hline 200 & vw & $\cdots$ & \\
\hline
\end{tabular}

a $\nu=$ stretching, $\delta=$ bending, $\gamma_{w}=$ wagging, $\gamma_{r}=$ rocking.

- Split in $n$-parafin spectra, with components at $2924 \mathrm{~cm}^{-1}$ and $2899 \mathrm{~cm}^{-1}$ d Split in $n$-paraffin spectra, with components at $2857 \mathrm{~cm}^{-1}$ and $2850 \mathrm{~cm}^{-1}$. 
KRIMM, LIANG, AND SUTHERLAND

TABLE II. Character table, number of normal modes, and selection rules for a single isolated polyethylene chain.

\begin{tabular}{|c|c|c|c|c|c|c|c|c|c|c|c|c|c|c|c|}
\hline$D_{2 h}$ & $E$ & $C_{2}(z)$ & $C_{2}(y)$ & $C_{2^{2}}(x)$ & $i$ & $\sigma(x y)$ & $\sigma(x z)$ & $\sigma(y z)$ & $n_{i}$ & $T$ & $T^{\prime}$ & $R^{\prime}$ & $n_{i}^{\prime}$ & $I R$ & $R$ \\
\hline $\begin{array}{l}A_{o} \\
B_{1 q} \\
B_{2 o} \\
B_{3 q} \\
A_{u} \\
B_{1 u} \\
B_{2 u} \\
B_{3 u}\end{array}$ & $\begin{array}{l}1 \\
1 \\
1 \\
1 \\
1 \\
1 \\
1 \\
1\end{array}$ & $\begin{array}{r}1 \\
1 \\
-1 \\
-1 \\
1 \\
1 \\
-1 \\
-1\end{array}$ & $\begin{array}{r}1 \\
-1 \\
1 \\
-1 \\
1 \\
-1 \\
1 \\
-1\end{array}$ & $\begin{array}{r}1 \\
-1 \\
-1 \\
1 \\
1 \\
-1 \\
-1 \\
1\end{array}$ & $\begin{array}{r}1 \\
1 \\
1 \\
1 \\
-1 \\
-1 \\
-1 \\
-1\end{array}$ & $\begin{array}{r}1 \\
1 \\
-1 \\
-1 \\
-1 \\
-1 \\
1 \\
1 \\
1\end{array}$ & $\begin{array}{r}1 \\
-1 \\
1 \\
-1 \\
-1 \\
1 \\
-1 \\
1\end{array}$ & $\begin{array}{r}1 \\
-1 \\
-1 \\
1 \\
-1 \\
1 \\
1 \\
-1\end{array}$ & $\begin{array}{l}3 \\
2 \\
1 \\
3 \\
1 \\
3 \\
3 \\
2\end{array}$ & $\begin{array}{c}0 \\
0 \\
0 \\
0 \\
0 \\
T_{z} \\
T_{y} \\
T_{x}\end{array}$ & $\begin{array}{c}1 \\
1 \\
0 \\
R_{x} \\
0 \\
0 \\
0 \\
0\end{array}$ & $\begin{array}{l}0 \\
1 \\
1 \\
1 \\
1 \\
1 \\
0 \\
1\end{array}$ & $\begin{array}{l}2 \\
0 \\
0 \\
1 \\
0 \\
1 \\
2 \\
0\end{array}$ & $\begin{array}{l}f^{a} \\
f \\
f \\
f \\
f \\
a \\
a \\
a\end{array}$ & $\begin{array}{l}\mathrm{p} \\
\mathrm{d} \\
\mathrm{d} \\
\mathrm{d} \\
\mathrm{f} \\
\mathrm{f} \\
\mathrm{f} \\
\mathrm{f}\end{array}$ \\
\hline
\end{tabular}

a f: forbidden, a: active, $p$ : polarized, $d$ : depolarized.

species. This implies knowledge of the normal vibrations of a single $\mathrm{CH}_{2}$ group, which we possess from the results of detailed studies on small molecules. The normal modes of a polyethylene chain, obtained in this way, are shown in Fig. 3. It will, of course, be realized that the relative amplitudes of motion of the various atoms are not determinable from symmetry considerations alone, but depend upon the particular masses and on the intramolecular force field. The normal modes of the component $\mathrm{CH}_{2}$ groups are, however, well known, as is also the relative phase of the motion in neighboring groups, ${ }^{1,17}$ viz., 0 or $\pi$. The modes can therefore be very closely approximated by the above procedure. The derivation of the normal modes of the chain from those of the component $\mathrm{CH}_{2}$ groups leads to a natural classification of the physical nature of the chain modes in terms of the corresponding group modes. This classification is shown in Table III, and refers to the modes pictured in Fig. 3. The expected polarization of the infrared active modes is indicated by $\sigma$, for perpendicular, and $\pi$, for parallel. The four zero frequencies, corresponding to the three translations and the rotation about the chain axis, are indicated respectively by $T_{x}, T_{y}, T_{z}$, and $R_{x}$ in Fig. 3 and Table III. It will be noted that, of the 5 infrared active fundamentals, 4 are expected to have perpendicular polarization, $\nu_{s}\left(\mathrm{CH}_{2}\right)\left(B_{2 u}\right), \nu_{a}\left(\mathrm{CH}_{2}\right) \quad\left(B_{1 u}\right), \delta\left(\mathrm{CH}_{2}\right)\left(B_{2 u}\right)$, and $\gamma_{r}\left(\mathrm{CH}_{2}\right)\left(B_{1 u}\right)$ and one is expected to have parallel polarization, $\gamma_{w}\left(\mathrm{CH}_{2}\right)\left(\mathrm{B}_{3 u}\right)$. The skeletal modes $A_{g}$ and $B_{1 \rho}$ are inactive in the infrared, as is the twisting frequency, $\gamma_{t}\left(\mathrm{CH}_{2}\right)$.

We have been concerned so far with the fundamental frequencies of an infinitely long chain of $\mathrm{CH}_{2}$ groups. In reality, the polyethylene chain is not infinitely long, and there is also evidence for some branching. Both of these effects account for the presence of $\mathrm{CH}_{3}$ groups, which can and do contribute appreciably to the spectrum. ${ }^{6}$ It will therefore be necessary to know which bands in the spectrum arise from $\mathrm{CH}_{3}$ groups. Since the $\mathrm{CH}_{3}$ groups are essentially randomly located in the specimen, it is most probable that there are no sharp selection rules for their fundamental frequencies. We would therefore expect to find in the spectrum fre-

17 Liang, Sutherland, and Krimm, J. Chem. Phys. 22, 1468 (1954). quencies assignable to the stretching, bending, wagging, and rocking motions of the hydrogen atoms in the $\mathrm{CH}_{3}$ group. These will be considered in greater detail in a succeeding section.

\section{B. Assignments of Active $\mathrm{CH}_{2}$ Fundamentals of Polyethylene Chain}

We now consider the correlation of the bands in the observed spectrum with those predicted from the theory. As mentioned previously, we will at present neglect the effects on the spectrum of neighboring chains in the crystal, since these effects are expected to be of secondary importance with respect to the assignment of fundamental frequencies. The results of considering these interactions will be discussed later. In what follows we shall deal only with the infrared active fundamentals.

The assignments for most of the bands in the spectrum have already been satisfactorily made. Thus, a detailed investigation of the $\nu_{a}\left(\mathrm{CH}_{2}\right)$ and $\nu_{s}\left(\mathrm{CH}_{2}\right)$ internal modes of the $\mathrm{CH}_{2}$ group in hydrocarbons and polyethylene ${ }^{6}$ has established the frequencies of these modes at $2926 \mathrm{~cm}^{-1}$ and $2853 \mathrm{~cm}^{-1}$, respectively. Similarly, it is well established ${ }^{18,19}$ that the $\delta\left(\mathrm{CH}_{2}\right)$ vibration gives rise to absorption at about $1460 \mathrm{~cm}^{-1}$. It may therefore be assumed that the strong band at about $1460 \mathrm{~cm}^{-1}$ in polyethylene is due mainly to this bending mode of the $\mathrm{CH}_{2}$ group. The rocking mode of the $\mathrm{CH}_{2}$ group, $\gamma_{r}\left(\mathrm{CH}_{2}\right)$, has been shown ${ }^{20,21}$ to give rise to the remaining intense band in the spectrum near $725 \mathrm{~cm}^{-1}$. (The doubling of this band in the spectrum will be considered later.) It will be noted that these frequencies have been predicted to be perpendicularly polarized and are observed to be so. (See Fig. 1.)

The assignment of the remaining active fundamental, the $\mathrm{CH}_{2}$ wagging mode, $\gamma_{w}\left(\mathrm{CH}_{2}\right)$, has not been as unequivocal as that of the four fundamentals just considered. Before discussing this assignment in detail, it may be well to review the reasons for the controversy

\footnotetext{
${ }^{18}$ G. Herzberg, Infrared and Raman Spectra (D. Van Nostrand Company, Inc., New York, 1945), p. 195.

${ }^{19}$ L. Kellner, Proc. Phys. Soc. (London) A64, 521 (1951).

${ }^{20}$ N. Sheppard and G. B. B. M. Sutherland, Nature 159, 739 (1947).

${ }^{21}$ G. B. B. M. Sutherland and A. Vallance Jones, Nature 160, 567 (1947).
} 
over it. As can be seen from our analysis, the $\gamma_{w}\left(\mathrm{CH}_{2}\right)$ mode is expected to show parallel polarization in the spectrum of an oriented sample. Two prominent parallel bands were found ${ }^{8}$ in the spectrum, at about $1375 \mathrm{~cm}^{-1}$ and $1303 \mathrm{~cm}^{-1}$. On the basis of a calculation of the expected normal frequencies of polyethylene, the more intense $1375 \mathrm{~cm}^{-1}$ band had been assigned ${ }^{22,23}$ to the $\gamma_{w}\left(\mathrm{CH}_{2}\right)$ mode. This assignment has been criticized, ${ }^{24}$ however, on the grounds that there is a well-established correlation ${ }^{7}$ between the $1375 \mathrm{~cm}^{-1}$ band and the $\mathrm{CH}_{3}$ group content of the specimen. These authors ${ }^{24}$ have accordingly preferred assigning the $1375 \mathrm{~cm}^{-1}$ band to a symmetrical $\mathrm{CH}_{3}$ bending mode, $\delta_{s}\left(\mathrm{CH}_{3}\right)$ and therefore assigning the $1303 \mathrm{~cm}^{-1}$ band to the $\gamma_{w}\left(\mathrm{CH}_{2}\right)$ mode. Although other authors ${ }^{25-27}$ have favored the former assignment, in spite of the $\mathrm{CH}_{3}$ group correlation, there has been presented no conclusive evidence for either choice. We will now discuss in detail an unambiguous assignment of the $\gamma_{w}\left(\mathrm{CH}_{2}\right)$ fundamental.

To begin with, it has been noted ${ }^{28}$ that the assignment of the $1303 \mathrm{~cm}^{-1}$ band to the $\gamma_{w}\left(\mathrm{CH}_{2}\right)$ fundamental is unsatisfactory because this band is present only when the molecule is in a disordered phase. This is illustrated

TABLE III. Classification of normal modes of polyethylene chain.

\begin{tabular}{|c|c|c|c|}
\hline Type of motion & Group mode & $\begin{array}{c}\text { Phase } \\
\text { between } \\
\text { groups }\end{array}$ & $\begin{array}{l}\text { Chain } \\
\text { mode }\end{array}$ \\
\hline \multirow[t]{3}{*}{$\begin{array}{l}\text { Internal hydrogen vibra- } \\
\text { tions of } \mathrm{CH}_{2} \text { group }\end{array}$} & $\begin{array}{l}\mathrm{CH}_{2} \text { symmetric } \\
\text { stretching, } \nu_{d}\left(\mathrm{CH}_{2}\right)\end{array}$ & $\begin{array}{l}0 \\
\pi\end{array}$ & $\begin{array}{l}A_{g} \\
B_{2 u}(\sigma)\end{array}$ \\
\hline & $\begin{array}{l}\mathrm{CH}_{2} \text { asymmetric } \\
\text { stretching, } \nu_{a}\left(\mathrm{CH}_{2}\right)\end{array}$ & $\begin{array}{l}0 \\
\pi\end{array}$ & $\begin{array}{l}B_{30} \\
B_{1 u}\end{array}(\sigma)$ \\
\hline & $\mathrm{CH}_{2}$ bending, $\delta\left(\mathrm{CH}_{2}\right)$ & 0 & $A_{0}$ \\
\hline \multirow[t]{3}{*}{$\begin{array}{l}\text { External hydrogen vibra- } \\
\text { tions of } \mathrm{CH}_{2} \text { group }\end{array}$} & $\mathrm{CH}_{2}$ wagging, $\gamma_{w}\left(\mathrm{CH}_{2}\right)$ & $\begin{array}{l}0 \\
\pi\end{array}$ & $\begin{array}{l}B_{3 u}(\pi) \\
B_{1 u}\end{array}$ \\
\hline & $\mathrm{CH}_{z}$ rocking, $\gamma_{r}\left(\mathrm{CH}_{2}\right)$ & $\begin{array}{l}0 \\
\pi\end{array}$ & $\begin{array}{l}B_{3 g} \\
B_{1 u}(\sigma)\end{array}$ \\
\hline & $\mathrm{CH}_{2}$ twisting, $\gamma_{\ell}\left(\mathrm{CH}_{2}\right)$ & $\begin{array}{l}0 \\
\pi\end{array}$ & $\begin{array}{l}A_{u} \\
B_{20}\end{array}$ \\
\hline \multirow[t]{3}{*}{$\begin{array}{l}\text { Skeletal vibrations }\left(\mathrm{CH}_{2}\right. \\
\text { group moving as a unit })\end{array}$} & $x$ direction & $\begin{array}{l}0 \\
\pi\end{array}$ & $\begin{array}{l}B_{3 u}\left(T_{x}\right) \\
B_{1 g}\end{array}$ \\
\hline & $y$ direction & $\begin{array}{l}0 \\
\pi\end{array}$ & $\begin{array}{l}A_{o} \\
B_{2 u}\left(T_{y}\right)\end{array}$ \\
\hline & $z$ direction & $\begin{array}{l}0 \\
\pi\end{array}$ & $\begin{array}{l}B_{3 g}\left(R_{x}\right) \\
B_{1 u}\left(T_{z}\right)\end{array}$ \\
\hline
\end{tabular}

${ }_{22}$ T. Simanouti, J. Chem. Phys. 17, 734 (1949).

${ }^{23} \mathrm{~T}$. Simanouti and S. Mizushima, J. Chem. Phys. 17, 1102 (1949).

${ }_{24}$ Brown, Sheppard, and Simpson, Discussions Faraday Soc. 9, 261 (1950).

${ }_{25}$ G. M. Barrow, J. Chem. Phys. 19, 345 (1951).

${ }^{26}$ W. B. Person and G. C. Pimentel, J. Am. Chem. Soc. 75, 532 (1953).

${ }^{27}$ H. Primas and H. H. Gunthard, Helv. Chim. Acta 36, 1791 (1953).

${ }^{28}$ S. Krimm, Phys. Rev. 94, 1426 (1954).

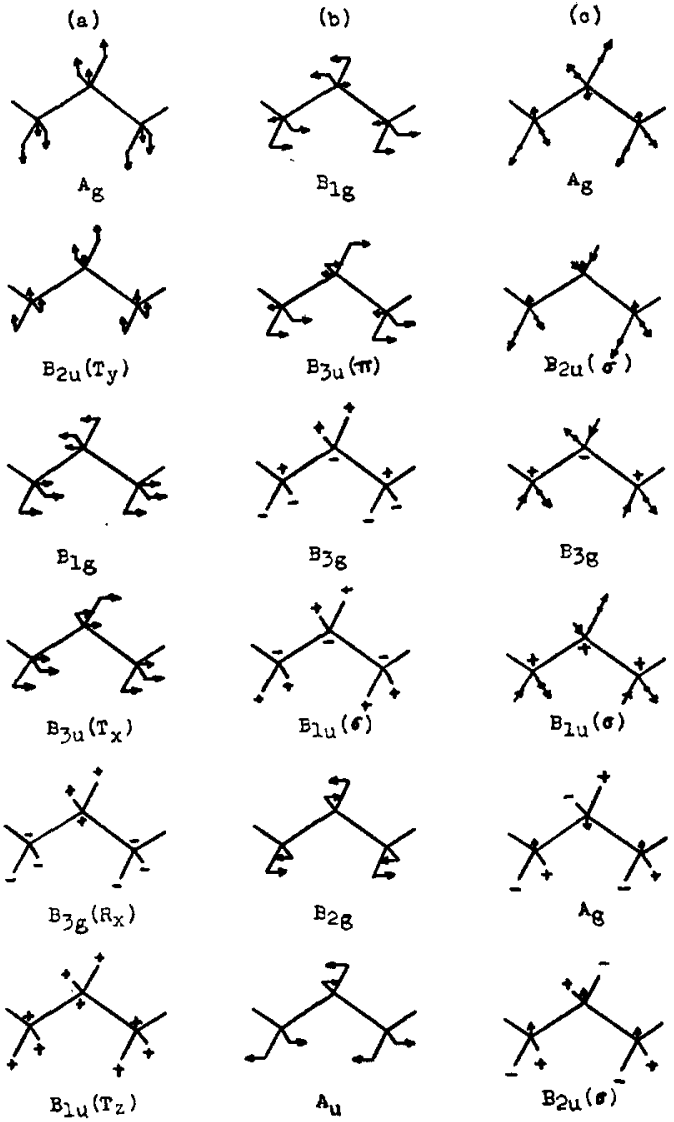

Fig. 3. Normal modes of a single polyethylene chain. Column (a): skeletal vibrations, (b) : external hydrogen vibrations of $\mathrm{CH}_{2}$ group, (c) : internal hydrogen vibrations of $\mathrm{CH}_{2}$ group.

in Fig. 4, which shows the spectrum of the $n$-paraffin $\mathrm{C}_{64} \mathrm{H}_{130}$, (a) in the solid state (as a polycrystalline aggregate deposited from the melt), (b) at its melting point, and (c) about $15^{\circ}$ above the melting point. It is seen that the $1303 \mathrm{~cm}^{-1}$ band is not present in the spectrum of the crystalline material, (a), which it should be if it arises from the $\gamma_{w}\left(\mathrm{CH}_{2}\right)$ mode of a planar zig-zag chain. (It will be shown later that this mode is also active when the full crystalline arrangement is considered instead of just a single chain.) Rather, the $1303 \mathrm{~cm}^{-1}$ band appears only when the sample is melted, thus indicating that it is not correlated with the planar zig-zag form of the chain but with the disordered configuration. Furthermore, the assignment of the 1303 $\mathrm{cm}^{-1}$ band to $\gamma_{w}\left(\mathrm{CH}_{2}\right)$ is not in agreement with the results of our examination of the spectra of a large variety of polymers which contain $\mathrm{CH}_{2}$ but no $\mathrm{CH}_{3}$ groups. We always find a band, which can be attributed to the $\gamma_{w}\left(\mathrm{CH}_{2}\right)$ mode as a result of its parallel polarization in stretched specimens, in the region of $1350-1370$ $\mathrm{cm}^{-1}$, never near $1300 \mathrm{~cm}^{-1}$. It therefore seems fairly conclusive that the $1303 \mathrm{~cm}^{-1}$ band cannot be assigned to the $\gamma_{w}\left(\mathrm{CH}_{2}\right)$ mode of a planar zig-zag chain.

Although, in the discussion of this assignment various authors ${ }^{7,8,22-27}$ have referred to the band at $1375 \mathrm{~cm}^{-1}$, 


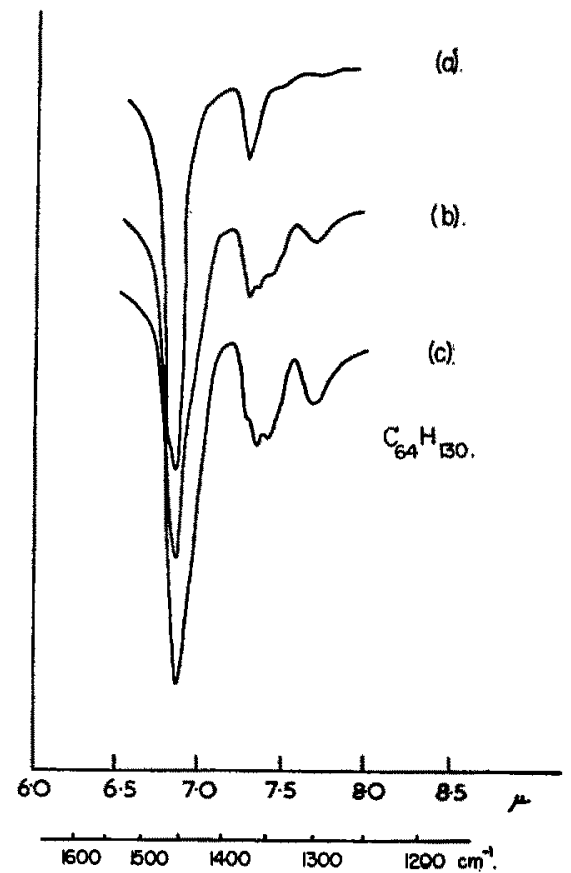

Fic. 4. Spectra of $n$ - $\mathrm{C}_{64} \mathrm{H}_{130}$ : (a) as a solid at room temperature, (b) as a liquid at the melting point, (c) about $15^{\circ}$ above the melting point.

it has become evident ${ }^{12}$ that this band is in reality a composite one. This has also been demonstrated especially clearly in the grating spectra of polyethylene, ${ }^{9}$ which show a structure similar to that in Fig. 4b. Peaks are found at 1375,1369 , and $1353 \mathrm{~cm}^{-1}$. It has also been noted ${ }^{12}$ that only the intensity of the 1375 $\mathrm{cm}^{-1}$ component (when measured in the liquid state) can be correlated with the $\mathrm{CH}_{3}$ group content, and it was therefore suggested that the two components at 1369 and $1353 \mathrm{~cm}^{-1}$ are associated with $\mathrm{CH}_{2}$ groups. Recent results ${ }^{29}$ on terminally deuterated $n$-octane confirm that the $1369 \mathrm{~cm}^{-1}$ band is associated with a $\mathrm{CH}_{2}$ group vibration and the results of our studies on single crystals of $n$-paraffins conclusively show that the $\gamma_{w}\left(\mathrm{CH}_{2}\right)$ mode of a planar zig-zag chain is to be assigned to this band.

In Fig. 5 we show the spectra of the crystalline $n$-paraffins $\mathrm{C}_{29} \mathrm{H}_{60}$ and $\mathrm{C}_{36} \mathrm{H}_{74}$. By means of $\mathrm{x}$-ray diffraction photographs, it was ascertained that the single crystals of $\mathrm{C}_{29} \mathrm{H}_{60}$ were in the usual orthorhombic form, ${ }^{30}$ while those of $\mathrm{C}_{36} \mathrm{H}_{74}$ were in the monoclinic form. ${ }^{31}$ The spectra under (a) were obtained from a solidified melt, and therefore represent a random aggregate of small crystals. The spectra shown under (b) were obtained from single crystals of the respective paraffins. (These curves are separated for purposes of clarity.) For the $\mathrm{C}_{29} \mathrm{H}_{60}$, the solid and broken curves in Fig. 5(b) represent spectra with the electric vector

${ }^{29}$ G. C. Pimentel and W. A. Klemperer, J. Chem. Phys. 23, 376 (1955).

${ }_{30}$ A. Muller, Proc. Roy Soc. (London) A120, 437 (1928).

a A. E. Smith, J. Chem. Phys. 21, 2229 (1953).

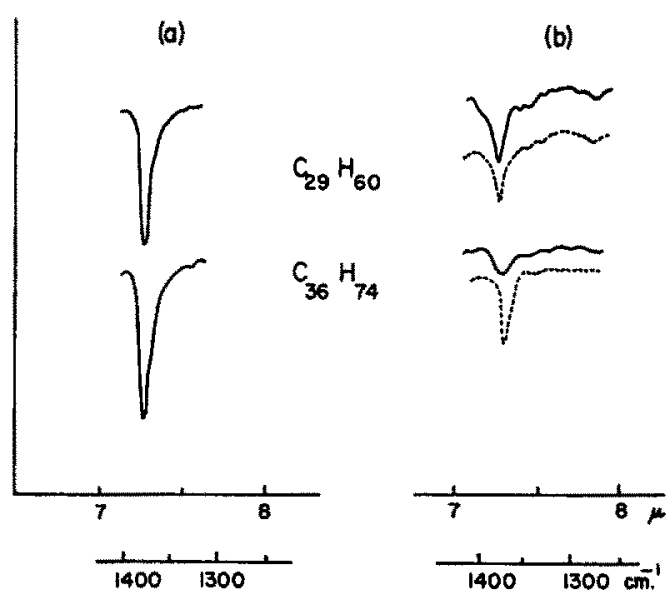

FIG. 5. Spectra of $n-\mathrm{C}_{29} \mathrm{H}_{60}$ and $n-\mathrm{C}_{36} \mathrm{H}_{74}$. (a) Sample solidified from the melt. (b) Single crystals: - radiation with electric vector polarized along $a$-axis, _. _. radiation with electric vector polarized along $b$-axis.

polarized along the $a$ and $b$ crystal axes, respectively. In this case, therefore, the radiation was directed along the $c$-axis of the single crystal, and the electric vector was always perpendicular to the chain axis. In the case of the $\mathrm{C}_{36} \mathrm{H}_{74}$, although the complete structure is not yet. known, it appears from preliminary results ${ }^{32}$ that the chain axis and the beam direction would make an angle of about $30^{\circ}$ with each other in our crystal, and therefore the electric vector could have a component along the chain axis direction. The solid and broken curves in Fig. $5 \mathrm{~b}$ represent in this case spectra with the electric vector polarized, respectively, along the crystal axis corresponding to the $a$ and the $b$ axes of the orthorhombic crystal.

The spectra in Fig. 5 show the following features. In the (a) spectra, corresponding to a random array of crystals, there is in both cases a strong peak at 1375 $\mathrm{cm}^{-1}$ with a weak shoulder near $1369 \mathrm{~cm}^{-1}$. No band is found near $1353 \mathrm{~cm}^{-1}$ or $1303 \mathrm{~cm}^{-1}$. The absence of the $1303 \mathrm{~cm}^{-1}$ band in crystalline paraffins, and therefore the rejection of its assignment to $\gamma_{w}\left(\mathrm{CH}_{2}\right)$, has been noted earlier. In the (b) spectra, we find for $\mathrm{C}_{29} \mathrm{H}_{60}$ only a single unpolarized band at $1375 \mathrm{~cm}^{-1}$, whereas for $\mathrm{C}_{36} \mathrm{H}_{74}$ we find two bands, one at $1375 \mathrm{~cm}^{-1}$ and the other at $1369 \mathrm{~cm}^{-1}$, the latter being more intense than the former. These results indicate that the $1369 \mathrm{~cm}^{-1}$ band is unquestionably the only band in this region which is polarized along the chain axis, and therefore it is the only possible one which can be assigned to $\gamma_{w}\left(\mathrm{CH}_{2}\right)$. The fact that this band is single, in accordance (as will be seen later) with the predicted spectrum based upon the full unit cell treatment, further substantiates this assignment.

The $1375 \mathrm{~cm}^{-1}$ band is undoubtedly the $\delta_{s}\left(\mathrm{CH}_{3}\right)$ frequency. We can also readily see that, as a result of the chain inclination, the $1369 \mathrm{~cm}^{-1}$ band should be

\footnotetext{
${ }^{32}$ A. E. Smith (private communication).
} 
relatively stronger in the spectrum of the $\mathrm{C}_{36} \mathrm{H}_{74}$ single crystal. The clarification of the apparent polarization of these two bands in the $\mathrm{C}_{36} \mathrm{H}_{74}$ single crystal spectrum must await a complete structure determination of the monoclinic form of $n$-paraffins.

These results, as well as those on melted paraffins shown in Fig. 4, indicate that the presence in the polyethylene spectrum of bands at $1353 \mathrm{~cm}^{-1}$ and $1303 \mathrm{~cm}^{-1}$ must be attributed to the fact that the material is partially amorphous. In fact, it seems quite probable that at least the $1353 \mathrm{~cm}^{-1}$ band is to be assigned to a $\mathrm{CH}_{2}$ wagging mode on chains in the amorphous regions. The shift in frequency from $1369 \mathrm{~cm}^{-1}$ is not unreasonable since the crystalline and amorphous chains represent different rotational isomers, which it is known $^{33,34}$ can have different frequencies. The presence of the 1369 $\mathrm{cm}^{-1}$ band in the spectrum of the liquid is not too surprising, since undoubtedly there are segments of chains which are essentially in a planar zig-zag configuration. This is particularly true near the melting point. ${ }^{35}$ The assignment of the $1353 \mathrm{~cm}^{-1}$ band to a $\mathrm{CH}_{2}$ wagging mode is substantiated by the observed parallel polarization of this band in stretched polyethylene, in which it is $\mathrm{known}^{4}$ that the amorphous regions are partially oriented with the chain axis parallel to the stretching direction. The fact that the $1303 \mathrm{~cm}^{-1}$ band is also found to have parallel polarization indicates that it too may be assignable to a $\mathrm{CH}_{2}$ wagging mode in the disordered phase. Another possibility is, however, the assignment to a $\mathrm{CH}_{2}$ twisting mode on an amorphous chain. We will discuss this later. It may be noted that the grating spectra ${ }^{9}$ show almost no polarization for the $1375 \mathrm{~cm}^{-1}$ peak. The parallel polarization which has been attributed to this band ${ }^{8}$ undoubtedly arises from the overlapping parallel band at $1369 \mathrm{~cm}^{-1}$. It is therefore unnecessary to postulate ${ }^{8}$ any special orientation of the $\mathrm{CH}_{3}$ groups in the crystalline regions of polyethylene.

There are some puzzling features about the intensities of the bands we have been discussing upon which it is worth remarking. In the first place, it is not immediately obvious why the intensity of the $\mathrm{CH}_{2}$ wagging mode should be so much weaker than that of the other $\mathrm{CH}_{2}$ group frequencies. This is apparently related to the magnitude of the dipole moment change during the vibration, since the weak intensity persists in the liquid state. It presumably was the impression that this mode should not be a weak one which led to the erroneous assignment of the $1375 \mathrm{~cm}^{-1}$ band to this vibration. We have furthermore observed that the $1375 \mathrm{~cm}^{-1}$ band, assigned to $\delta_{s}\left(\mathrm{CH}_{3}\right)$, is itself of variable intensity in the $n$-paraffins. An examination of the spectra of the $n$-paraffins $\mathrm{C}_{27} \mathrm{H}_{56}, \mathrm{C}_{28} \mathrm{H}_{58}, \mathrm{C}_{29} \mathrm{H}_{60}$, and $\mathrm{C}_{30} \mathrm{H}_{62}$ as poly-

${ }^{33}$ J. K. Brown and N. Sheppard, Discussions Faraday Soc. 9, 144 (1950).

${ }_{34}$ J. K. Brown and N. Sheppard, Trans. Faraday Soc. 50, 535 (1954).

${ }^{35}$ B. E. Warren, Phys. Rev. 44, 969 (1933). crystalline solid films deposited from the melt reveals the following facts. In the $\mathrm{C}_{27} \mathrm{H}_{56}$ and $\mathrm{C}_{29} \mathrm{H}_{60}$ spectra there is a band at $1375 \mathrm{~cm}^{-1}$ with a shoulder on the low frequency side at $1369 \mathrm{~cm}^{-1}$, as indicated in Fig. 4 . The ratio of the optical density at the peak of the 1460 $\mathrm{cm}^{-1} \delta\left(\mathrm{CH}_{2}\right)$ band to that at the peak of the $1375 \mathrm{~cm}^{-1}$ band is in both cases about 3.3:1. In the $\mathrm{C}_{28} \mathrm{H}_{58}$ and $\mathrm{C}_{30} \mathrm{H}_{62}$ spectra, on the other hand, there is only a single symmetrical peak at $1369 \mathrm{~cm}^{-1}$ with no component at $1375 \mathrm{~cm}^{-1}$, and the ratio of the 1460 to 1369 peak optical densities in this case is about $9.5: 1$. In other words, it would appear from these results that the $\delta_{s}\left(\mathrm{CH}_{3}\right)$ vibration is considerably weaker in crystalline paraffins with an even number of carbon atoms in the chain than in those with an odd number. This has also been observed $^{9}$ in the spectrum of $\mathrm{C}_{18} \mathrm{H}_{38}$. (This conclusion is not altered by making allowance in the prism spectra for the small $\delta_{a}\left(\mathrm{CH}_{3}\right)$ contribution to the $1460 \mathrm{~cm}^{-1}$ band.) It would seem natural to try to account for these observations in terms of the differing interactions between adjacent $\mathrm{CH}_{3}$ groups on neighboring chains in the crystal. This is not unreasonable, since the relative orientation of two such methyl groups is different for chains with an even number of carbon atoms than for chains with an odd number of carbon atoms. This explanation, however, cannot be the complete one, since in the case of the even paraffins $\mathrm{C}_{36} \mathrm{H}_{74}$ and $\mathrm{C}_{64} \mathrm{H}_{130}$ we also find the $1375 \mathrm{~cm}^{-1}$ band (see Figs. 4 and 5). The corresponding optical density ratio in both cases is about 9.5:1. A similar observation has been noted ${ }^{9}$ for $\mathrm{C}_{48} \mathrm{H}_{98}$. These results indicate that other factors, perhaps the crystal form, are also important. They point up the fact that our understanding of the factors determining the intensities of bands in the crystalline state is very incomplete. Indeed, until we understand more fully the factors affecting the intensity of the $\delta_{s}\left(\mathrm{CH}_{3}\right)$ vibration, it may be desirable to exercise caution in interpreting the results of $\mathrm{CH}_{3}$ group determinations in polyethylene obtained by means of the intensity of this band. ${ }^{12,36}$

Finally, we will consider the assignments of the $\mathrm{CH}_{3}$ group frequencies, which make a significant contribution to the polyethylene spectrum. In doing so we will assume that the $\mathrm{CH}_{3}$ groups are randomly distributed in the sample. We may note that, contrary to this view, it has been suggested, ${ }^{37}$ on the basis of the decrease in intensity of the $1375 \mathrm{~cm}^{-1}$ band on melting, that the $\mathrm{CH}_{3}$ groups are in the crystalline regions of the polymer. This conclusion, however, may not be completely unambiguous when we consider that we yet do not understand the factors which determine the intensity of this fundamental. We have already noted that even the intensity variation of this band in crystals is not entirely simple. It is, therefore, justifiable to consider that we are dealing with independent

${ }^{36}$ W. M. D. Bryant and R. C. Voter, J. Am. Chem. Soc. 75, 6113 (1953).

${ }^{37}$ R. B. Richards, J. Appl. Chem. (London) 1, 370 (1951). 


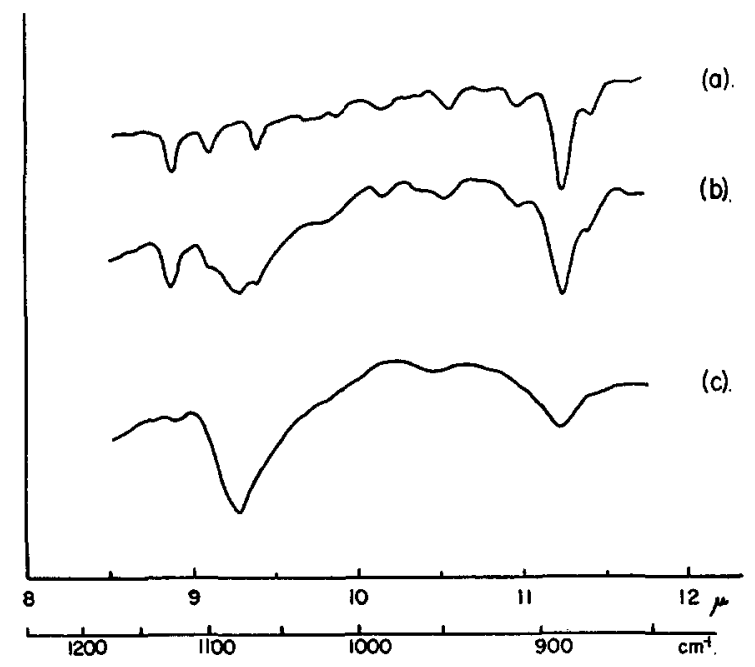

FIG. 6. Spectra of $n$ - $\mathrm{C}_{36} \mathrm{H}_{74}$ : (a) as polycrystalline solid at room temperature; $(b)$ as a liquid at the melting point; $(c)$ about $15^{\circ}$ above the melting point.

$\mathrm{CH}_{3}$ groups, such as would be present in the amorphous phase. We thus expect that to each $\mathrm{CH}_{3}$ group can be associated 7 fundamentals: the symmetrical, $\nu_{s}\left(\mathrm{CH}_{3}\right)$, and asymmetrical, $\nu_{a}\left(\mathrm{CH}_{3}\right)$, internal hydrogen stretching modes; the symmetrical $\delta_{s}\left(\mathrm{CH}_{3}\right)$, and asymmetrical, $\delta_{a}\left(\mathrm{CH}_{3}\right)$, internal hydrogen bending modes; and the external rocking, $\gamma_{r}\left(\mathrm{CH}_{3}\right)$, wagging $\gamma_{w}\left(\mathrm{CH}_{3}\right)$, and twisting, $\gamma_{t}\left(\mathrm{CH}_{3}\right)$, modes.

The $\nu_{8}\left(\mathrm{CH}_{3}\right)$ and $\nu_{a}\left(\mathrm{CH}_{3}\right)$ frequencies have been established by Fox and Martin ${ }^{6}$ at 2872 and $2962 \mathrm{~cm}^{-1}$ respectively. In our polyethylene spectrum we only find a shoulder at $2959 \mathrm{~cm}^{-1}$, which is presumably the $\nu_{a}\left(\mathrm{CH}_{3}\right)$ mode. The $\nu_{s}\left(\mathrm{CH}_{3}\right)$ mode is less intense, and we do not detect it in our prism spectra. Both bands have been found, however, in grating spectra, ${ }^{9}$ where they occur at $2874 \mathrm{~cm}^{-1}$ and $2959 \mathrm{~cm}^{-1}$ respectively. The two internal bending modes are also well established, the $\delta_{s}\left(\mathrm{CH}_{3}\right)$ mode as we have seen, at $1375 \mathrm{~cm}^{-1}$ and the $\delta_{a}\left(\mathrm{CH}_{3}\right)$ mode $^{18,19}$ at about $1460 \mathrm{~cm}^{-1}$.

Of the external deformation frequencies of the $\mathrm{CH}_{3}$ group, we expect that the twisting mode will be very

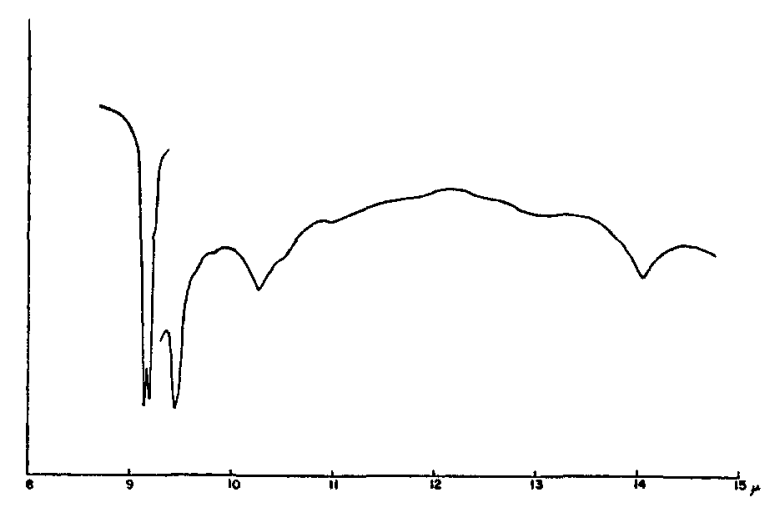

Fig. 7. Spectrum of deuteroparaffin (approximate composition $\mathrm{C}_{100} \mathrm{D}_{202}$ ). weak, if not inactive. We have assumed that it is not detectable in the spectrum. We will consider now the assignment of the rocking and wagging modes. In terms of the plane of the carbon chain adjoining a $\mathrm{CH}_{3}$ group, we term the rocking mode as the deformation taking place perpendicular to this plane and the wagging mode as the one which occurs in the plane. We will consider first the location of these two frequencies from an examination of the spectra of the $n$-paraffins. These frequencies are expected to occur in the range between $800 \mathrm{~cm}^{-1}$ to $1200 \mathrm{~cm}^{-1}$, which is shown in Fig. 6 for the $n$-paraffin $\mathrm{C}_{36} \mathrm{H}_{74}$. Curve (a) is the spectrum of the polycrystalline solid at room temperature, curve (b) is of the material as a liquid at its melting point, and curve (c) is of the material at about $15^{\circ}$ above its melting point. The prominent band at $890 \mathrm{~cm}^{-1}$, found in polyethylene at $888 \mathrm{~cm}^{-1}$, can immediately be assigned to a $\mathrm{CH}_{3}$ frequency for the following reasons: (1) In our spectrum of the deuteroparaffin $\mathrm{C}_{100} \mathrm{D}_{202}$, shown in Fig. 7 , this band has shifted to $711 \mathrm{~cm}^{-1}$, just about the amount expected for a $\mathrm{CH}_{3}$ frequency; (2) A correlation is found ${ }^{12}$ between the intensity of this band and the $\mathrm{CH}_{3}$ group content of the hydrocarbon; (3) The band is relatively unchanged, compared to neighboring bands, on passing from the solid to the liquid state, as can be seen from Fig. 6. The significance of the latter point is that skeletal frequencies of the planar zig-zag carbon chain, which are also expected to occur in this region, are most likely to be affected by a change of state, since the skeletal configuration is thereby altered. This has also been observed in the Raman spectra of $n$-paraffins. ${ }^{38}$ We therefore assign as $\mathrm{CH}_{3}$ frequencies those bands which are least affected by a change in state. (It might be noted that although the skeletal frequencies are predicted to be inactive for an infinite chain, they can show activity in finite chains. ${ }^{19}$ )

As to the other $\mathrm{CH}_{3}$ frequency, the above argument about band constancy with change in state, and knowledge $^{39}$ of the expected region for such modes, leads us to

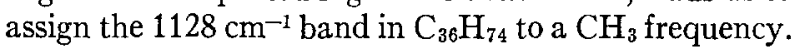
In all of the spectra of $n$-paraffins which we have examined, a band is found within $2 \mathrm{~cm}^{-1}$ of this value. There also appears to be some support for this assignment from studies on terminally deuterated $n$-octane..$^{29}$ Thus we assign the $\mathrm{CH}_{3}$ modes to bands at about 890 $\mathrm{cm}^{-1}$ and $1128 \mathrm{~cm}^{-1}$. It has been claimed ${ }^{10}$ that the absorption band in polyethylene at $543 \mathrm{~cm}^{-1}$ is correlated with the $\mathrm{CH}_{3}$ content of the sample. We have been unable to detect this band in suitably thick samples of the $n$-paraffin $\mathrm{C}_{36} \mathrm{H}_{74}$, and therefore think that it is unlikely that it represents a $\mathrm{CH}_{3}$ frequency. Furthermore, it does not seem to be in an appropriate region, even for a torsional mode. ${ }^{40}$

The assignment of the two $\mathrm{CH}_{3}$ frequencies at 890

${ }^{38}$ S. Mizushima and T. Simanouti, J. Am. Chem. Soc. 71, 1320 (1949).

${ }^{30}$ R. S. Rasmussen, J. Chem. Phys. 16, 712 (1948).

${ }^{40}$ K. S. Pitzer, J. Chem. Phys. 12, 310 (1944). 
TABLE IV. Character table, number of normal modes, and selection rules for crystalline polyethylene.

\begin{tabular}{|c|c|c|c|c|c|c|c|c|c|c|c|c|c|c|c|}
\hline$D_{2 h}$ & $E$ & $C_{2^{s}}(a)$ & $C_{2^{e}}(b)$ & $C_{2^{\prime}}(c)$ & $i$ & $\sigma_{\theta}(b c)$ & $\sigma_{g}(a c)$ & $\sigma(a b)$ & $n_{i}$ & $T$ & $T^{\prime}$ & $R^{\prime}$ & $n_{i}^{\prime}$ & $I R$ & $R$ \\
\hline $\begin{array}{l}A_{g} \\
B_{1 q} \\
B_{2 g} \\
B_{3 q} \\
A_{u} \\
B_{1 u} \\
B_{2 u} \\
B_{3 u}\end{array}$ & $\begin{array}{l}1 \\
1 \\
1 \\
1 \\
1 \\
1 \\
1 \\
1\end{array}$ & $\begin{array}{r}1 \\
1 \\
-1 \\
-1 \\
1 \\
1 \\
-1 \\
-1\end{array}$ & $\begin{array}{r}1 \\
-1 \\
1 \\
-1 \\
1 \\
-1 \\
1 \\
-1\end{array}$ & $\begin{array}{r}1 \\
-1 \\
-1 \\
1 \\
1 \\
-1 \\
-1 \\
1\end{array}$ & $\begin{array}{r}1 \\
1 \\
1 \\
1 \\
-1 \\
-1 \\
-1 \\
-1 \\
-1\end{array}$ & $\begin{array}{r}1 \\
1 \\
-1 \\
-1 \\
-1 \\
-1 \\
1 \\
1\end{array}$ & $\begin{array}{r}1 \\
-1 \\
1 \\
-1 \\
-1 \\
1 \\
-1 \\
1\end{array}$ & $\begin{array}{r}1 \\
-1 \\
-1 \\
1 \\
-1 \\
1 \\
1 \\
-1\end{array}$ & $\begin{array}{l}6 \\
3 \\
3 \\
6 \\
3 \\
6 \\
6 \\
3\end{array}$ & $\begin{array}{c}0 \\
0 \\
0 \\
0 \\
0 \\
T_{a} \\
T_{b} \\
T_{c}\end{array}$ & $\begin{array}{l}2 \\
1 \\
1 \\
2 \\
1 \\
1 \\
1 \\
0\end{array}$ & $\begin{array}{l}1 \\
2 \\
2 \\
1 \\
2 \\
1 \\
1 \\
2\end{array}$ & $\begin{array}{l}3 \\
0 \\
0 \\
3 \\
0 \\
3 \\
3 \\
0\end{array}$ & $\begin{array}{l}\mathrm{f}^{\mathbf{a}} \\
\mathrm{f} \\
\mathrm{f} \\
\mathbf{f} \\
\mathrm{f} \\
\mathbf{a} \\
\mathbf{a} \\
\mathbf{a}\end{array}$ & $\begin{array}{l}\mathrm{p} \\
\mathrm{d} \\
\mathrm{d} \\
\mathrm{d} \\
\mathrm{f} \\
\mathrm{f} \\
\mathrm{f} \\
\mathrm{f}\end{array}$ \\
\hline
\end{tabular}

see reference a in Table II.

and $1128 \mathrm{~cm}^{-1}$ to the rocking and wagging motions has now to be considered. If the disposition of $\mathrm{CH}_{3}$ groups in oriented polyethylene were known, we could use the observed dichroism of these bands to assist in making the assignment. Unfortunately, we cannot assume this knowledge. Similarly, complete knowledge of the structure of the monoclinic form of paraffins would be helpful, since we observe that in a single crystal of orthorhombic $\mathrm{C}_{29} \mathrm{H}_{60}$ the $890 \mathrm{~cm}^{-1}$ band appears with about the same relative intensity as in the polycrystalline solid, whereas in a single crystal of monoclinic $\mathrm{C}_{36} \mathrm{H}_{74}$ (which is viewed at an angle to the chain axis) this band is considerably weaker. It seems likely, nevertheless, just from consideration of the restoring forces involved in the two motions, that we should assign the $890 \mathrm{~cm}^{-1}$ band to the out-of-plane mode, $\gamma_{r}\left(\mathrm{CH}_{3}\right)$, and the 1128 $\mathrm{cm}^{-1}$ band to the in-plane mode, $\gamma_{w}\left(\mathrm{CH}_{3}\right)$. This would be in agreement with conclusions reached from a study of short chain $n$-paraffins. ${ }^{41}$

\section{Predicted Spectrum of Crystalline Polyethylene}

We have already noted that although the main features of the spectrum of polyethylene can be predicted from consideration of a single chain, a complete interpretation must take account of the actual crystal structure of the material. We will consider now this more complete analysis. A comparison of the two treatments should serve as a guide to what may be expected in the spectra of other polymers.

The procedure for the group theory analysis is similar to that discussed for the case of the single chain. ${ }^{2,15,16} \mathrm{~A}$ cross section of the unit cell of crystalline polyethylene, ${ }^{2}$ perpendicular to the $c$-axis (chain axis) and bisecting a $\mathrm{C}-\mathrm{C}$ bond, is shown in Fig. 8. The $\mathrm{CH}_{2}$ groups lie in planes parallel to the $a b$ plane, and in Fig. 8 they are indicated as being above (solid line) and below (dashed line) the plane of the section. The structure belongs to the space group $D_{2 h}{ }^{16}$, which has a factor group isomorphous with the point group $D_{2 h}$. The character table, number of normal modes, and selection rules are given in Table IV, the symbols having the same meaning as those in Table II. As in the case

${ }^{41}$ Brown, Sheppard, and Simpson, Trans. Roy. Soc. (London) A247, 35 (1954). of the single chain, approximate normal modes can be derived from the symmetry species. These are shown in Figs. 9, 10, and 11, and they are classified in Table V. The motions indicated by arrows take place parallel to the $a b$ plane, those indicated by plus and minus signs take place perpendicular to this plane. As can be seen from Table IV, $B_{1 u}$ and $B_{2 u}$ modes will be polarized perpendicular to the chain axis while $B_{3 u}$ modes will be polarized parallel to this axis.

The factor group analysis predicts 12 infrared active fundamentals in the spectrum of crystalline polyethylene. In comparing these with the fundamentals predicted for a single chain, the following differences are to be noted: (1) All of the single chain modes which exhibited polarization perpendicular to the chain axis are split into two components in the crystal. Of these, as will be readily seen from Figs. 10 and 11, the $B_{1 u}$ modes are polarized along the $a$-axis of the crystal and the $B_{2 u}$ modes are polarized along the $b$-axis. The extent of the splitting, and therefore the possibility of observing the two components in the spectrum, cannot of course be determined from symmetry considerations alone. It depends upon the nature and magnitude of the forces which are involved. (2) The parallel polarized $\gamma_{w}\left(\mathrm{CH}_{2}\right)$ mode is not split in the infrared spectrum of the crystal. (3) $\mathrm{A} \mathrm{CH}_{2}$ twisting mode, inactive in a single chain, is predicted to be active in the crystal.

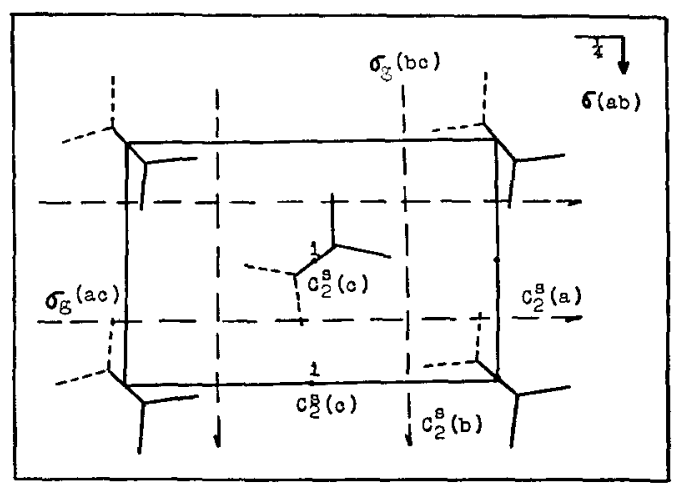

FIG. 8. Cross section of unit cell of polyethylene perpendicular to $c$-axis and bisecting $\mathrm{C}-\mathrm{C}$ bond. $\mathrm{C}_{2}{ }^{3}-$ screw diad, $\sigma-$ mirror plane, $\sigma_{g}-$ glide plane ( $\sigma_{g}$ is a diagonal glide plane, with translation $(b+c) / 2), i$-center of inversion. $\mathrm{CH}_{2}$ groups are indicated as above (solid V) and below (dashed V) the plane. 

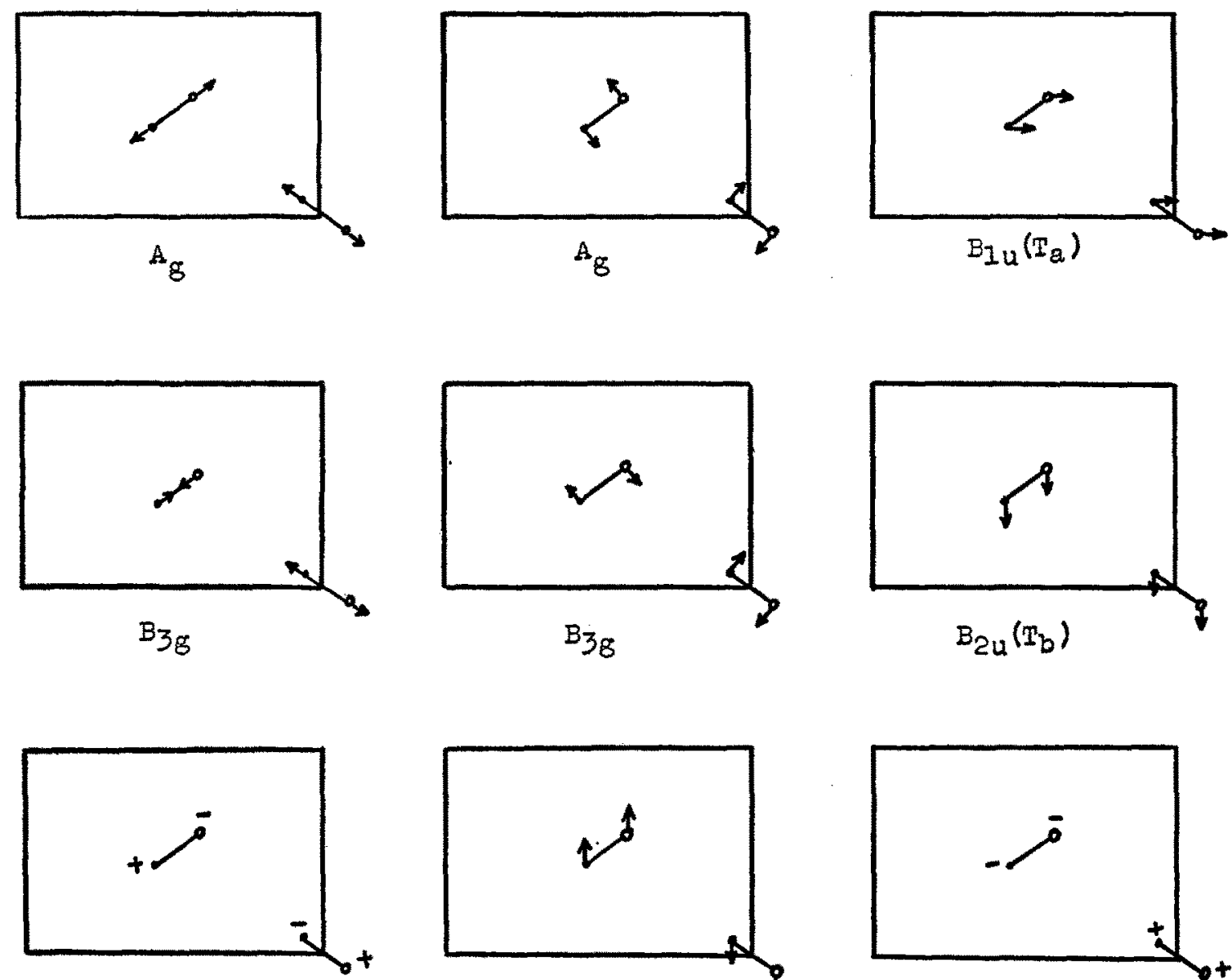

$B_{18}$
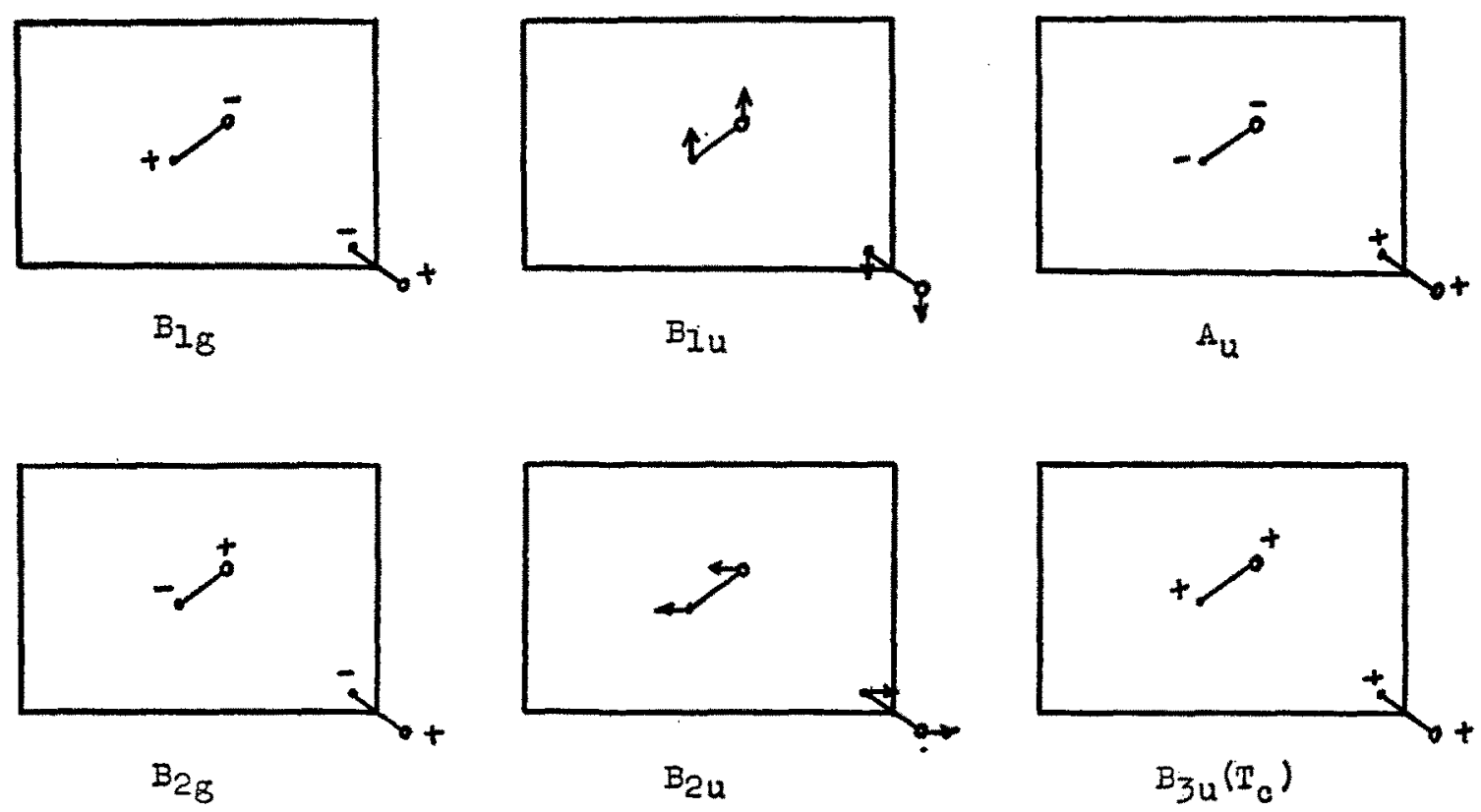

FrG. 9. Normal modes of polyethylene unit cell: translations $(T)$ and translatory-type vibrations $\left(T^{\prime}\right)$.

(4) Two lattice modes, $B_{1 u}$ and $B_{2 u}$, are predicted to be active in the crystal. Since these modes are expected to be at a very low frequency, they have probably not been observed in the range covered by the present work.

Thus, as a result of the transition from the single chain to the crystal, we find a splitting of some of the fundamental frequencies and activity predicted for some previously inactive frequencies. The interactions which lead to a splitting of frequencies in the crystal will not drastically change the positions of the funda- mental frequencies. ${ }^{42}$ It is for this reason that we can carry through a satisfactory assignment based on the analysis of a single chain. The activity in the crystal spectrum of modes which are inactive in a single chain is a result of the change in the symmetry of the potential field of the molecule. Although such activity can result, it will rarely, if ever, happen that a fundamental which is predicted to be active in the single chain

${ }^{42}$ D. F. Hornig, Discussions Faraday Soc. 9, 115 (1950). 
(a)
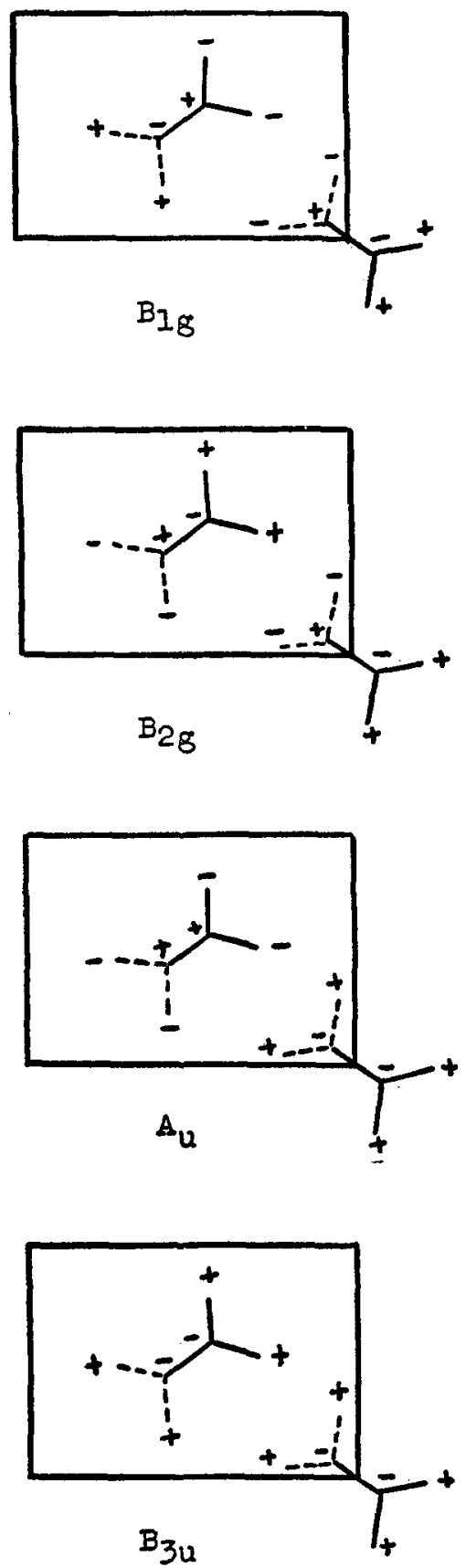

(b)
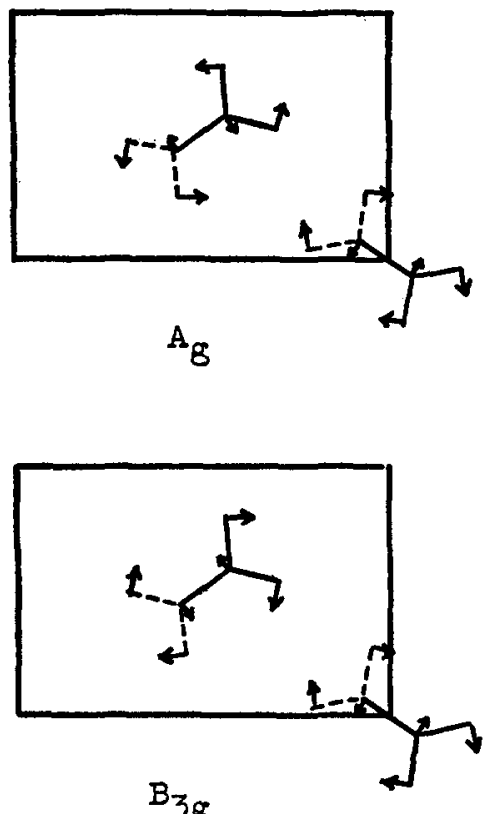

$\mathrm{B}_{38}$

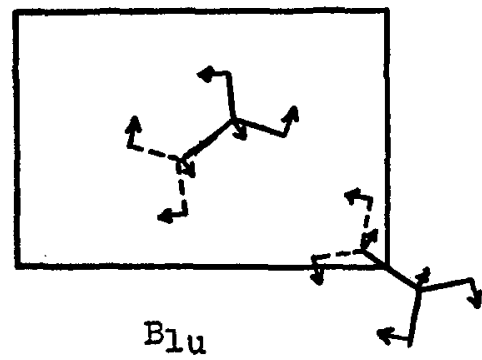

Blu

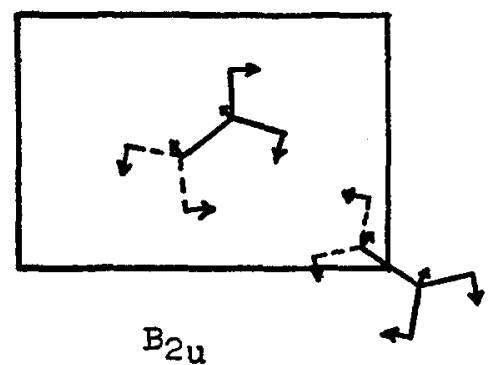

(c)
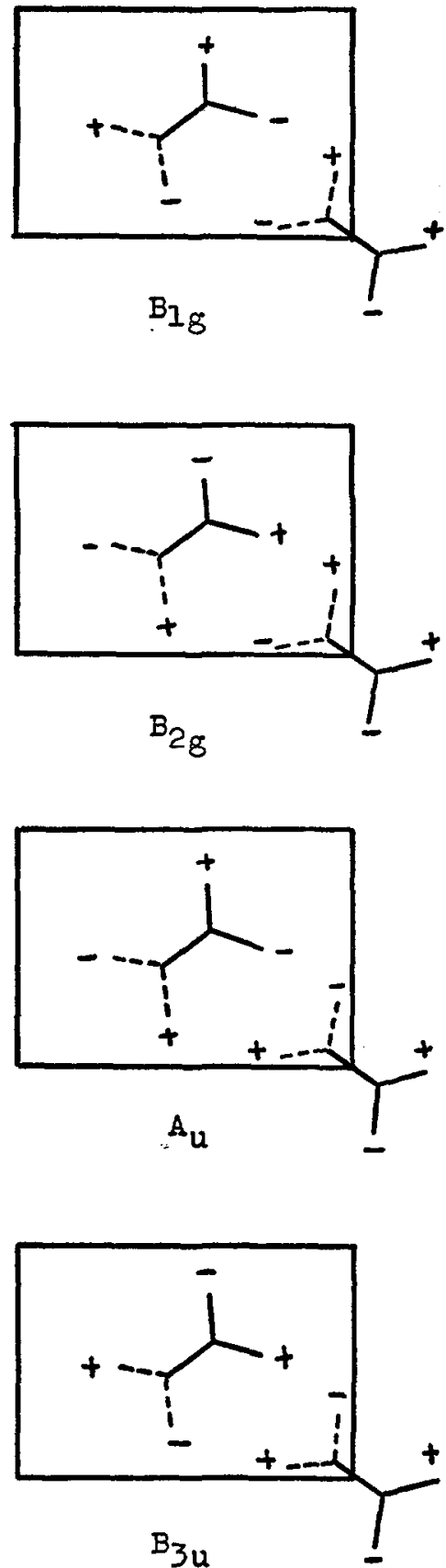

FIG. 10. Normal modes of polyethylene unit cell: rotatory-type vibrations $\left(R^{\prime}\right)$.

becomes inactive in the crystal. ${ }^{1}$ This further justifies the use of the single chain analysis.

\section{E. Assignments of Frequencies in Crystalline Polyethylene}

We wish to consider now those features of the spectrum of polyethylene which cannot be accounted for on the basis of a single chain analysis. Most prominent among these is the evident doubling in the band at about $725 \mathrm{~cm}^{-1}$, the $\gamma_{r}\left(\mathrm{CH}_{2}\right)$ mode, and the similar effect obtained at $1460 \mathrm{~cm}^{-1}$ in the $\delta\left(\mathrm{CH}_{2}\right)$ mode. ${ }^{43,44}$ We will show that these effects are associated with the crystalline regions of polyethylene, and follow from the results of the factor group analysis.

It has been suggested ${ }^{43,44}$ that the splitting of the

${ }^{43}$ R. S. Stein and G. B. B. M. Sutherland, J. Chem. Phys. 21, 370 (1953).

${ }_{44}$ R. S. Stein and G. B. B. M. Sutherland, J. Chem. Phys. 22, 1993 (1954). 
(a)
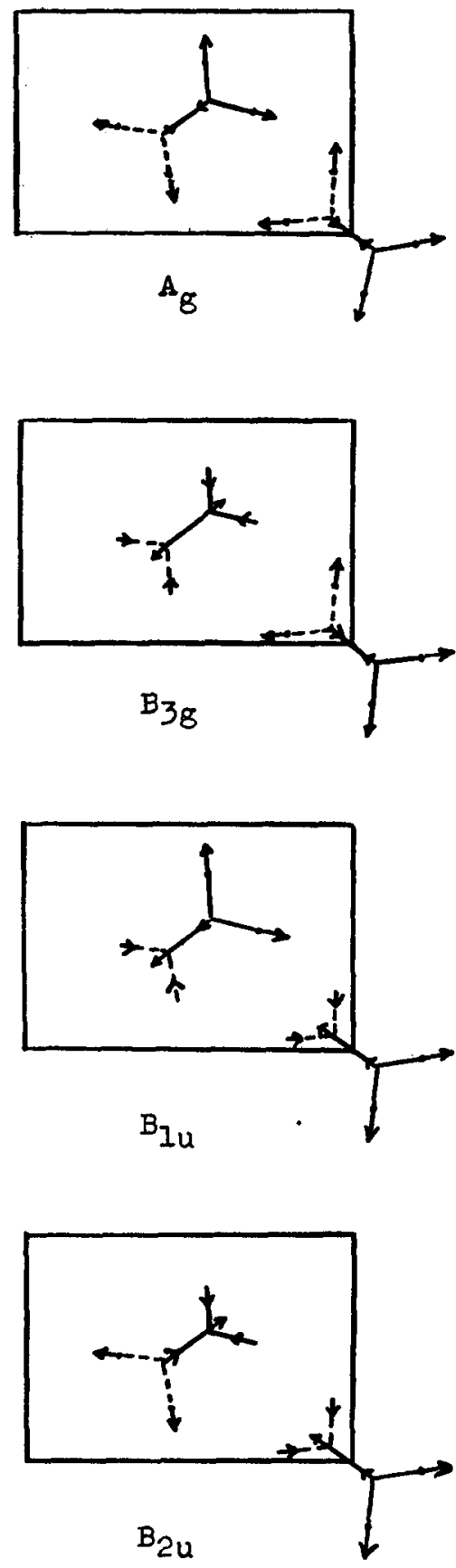

(b)
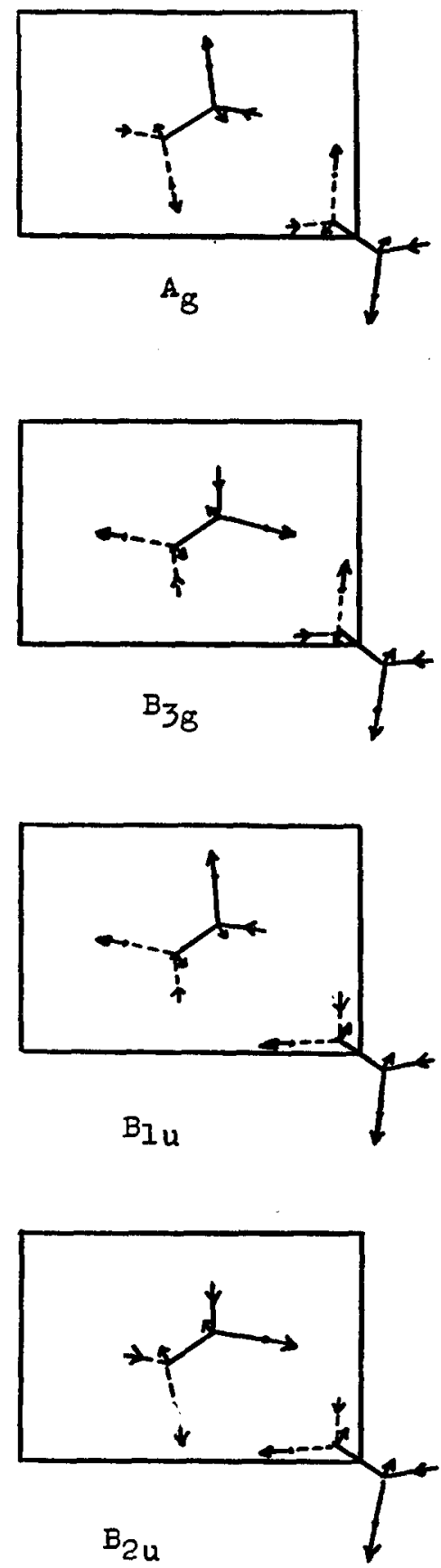

(c)
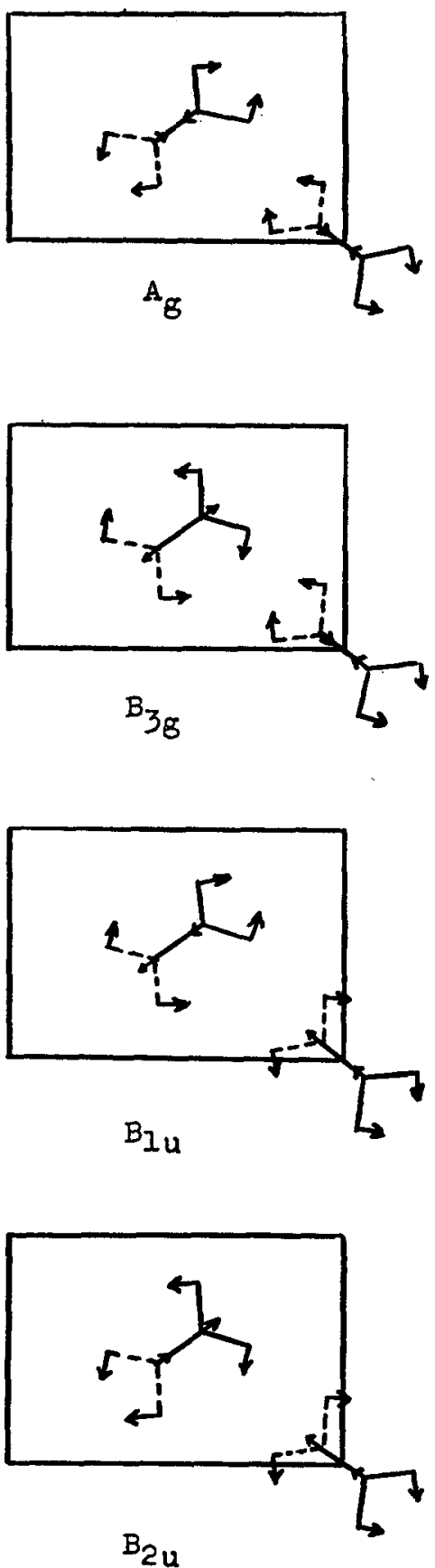

FIG. 11. Normal modes of polyethylene unit cell: internal vibrations $\left(n_{i}{ }^{\prime}\right)$.

$\gamma_{r}\left(\mathrm{CH}_{2}\right)$ mode into two components at $721 \mathrm{~cm}^{-1}$ and $731 \mathrm{~cm}^{-1}$ arises from interactions between adjacent molecules in the crystalline phase which results in both an in-phase and an out-of-phase rocking mode. This is also predicted from the group theory analysis, which shows that the $B_{1 u}$ mode will be polarized along the $a$-axis of the crystal and the $B_{2 u}$ mode along the $b$-axis. An obvious test of this hypothesis would be to examine the polarization of these components in a single crystal, with radiation directed along the $c$-axis. This has been done, ${ }^{4}$ and we indeed find such specific polarization for the components, viz., the $721 \mathrm{~cm}^{-1}$ band polarized along the $b$-axis and the $731 \mathrm{~cm}^{-1}$ band polarized along the $a$-axis. The crystal which was examined, ${ }^{4}$ viz., $\mathrm{C}_{36} \mathrm{H}_{74}$, was in the monoclinic form. We have also examined a single crystal of orthorhombic $\mathrm{C}_{29} \mathrm{H}_{60}$ and find exactly the same results.

Further evidence that this splitting arises from an 
TABle V. Classification of normal modes of crystalline polyethylene.

\begin{tabular}{|c|c|c|c|}
\hline \multirow[b]{2}{*}{ Type of motion } & \multirow[b]{2}{*}{ Species } & \multicolumn{2}{|c|}{ Illustrated in } \\
\hline & & Figure & Column \\
\hline Translations & $B_{1 u}, B_{2 u}, B_{3 u}$ & 9 & c \\
\hline Lattice modes & & & \\
\hline (a) Translatory & $\begin{array}{l}B_{1 u}, B_{2 u} \\
A_{u}\end{array}$ & $\begin{array}{l}9 \\
9\end{array}$ & $\mathrm{~b}$ \\
\hline (b) Rotatory & $A_{g}, B_{3 g}$ & 9 & b \\
\hline Skeletal vibrations & $A_{g}, B_{3 q}, B_{1 q}, B_{2 q}$ & 9 & $\mathrm{a}$ \\
\hline External $\mathrm{CH}_{2}$ modes & & & \\
\hline $\begin{array}{l}\text { (a) } \mathrm{CH}_{2} \text { wagging } \\
\text { (b) } \mathrm{CH}_{2} \text { rocking }\end{array}$ & $\begin{array}{l}B_{1 g}, B_{2 g}, A_{u}, B_{3 u} \\
A^{\prime}, B_{3 o}, B_{1 u} B_{2 u}\end{array}$ & $\begin{array}{l}10 \\
10\end{array}$ & $\begin{array}{l}\mathrm{a} \\
\mathrm{b}\end{array}$ \\
\hline (c) $\mathrm{CH}_{2}$ twisting & $B_{1 \sigma}, B_{2 q} A_{u}, B_{2 u}$ & 10 & c \\
\hline Internal $\mathrm{CH}_{2}$ modes & & & \\
\hline (a) $\mathrm{CH}_{2}$ sym. stretching & $A_{o}, B_{3 q}, B_{1 u}, B_{2 u}$ & 11 & a \\
\hline (b) $\mathrm{CH}_{2}$ asym. stretching & $A_{g}, B_{3 q}, B_{1 u}, B_{2 u}$ & 11 & $\mathrm{~b}$ \\
\hline (c) $\mathrm{CH}_{2}$ bending & $A_{g}, B_{3 q}, B_{1 u}, B_{2 u}$ & 11 & c \\
\hline
\end{tabular}

interaction between chains in the crystal is provided by a study of solid solutions of a paraffin in a deuteroparaffin. ${ }^{28}$ In Fig. 12 are shown the spectra in the 725 $\mathrm{cm}^{-1}$ region of a series of solid solutions of $\mathrm{C}_{64} \mathrm{H}_{130}$ in a deuteroparaffin whose formula is approximately $\mathrm{C}_{100} \mathrm{D}_{202}$. The broken curve represents a melt of pure $\mathrm{C}_{64} \mathrm{H}_{120}$. A number of observations can be made. (1) In a dilute enough solution, such as $1: 20$ by weight, the $\gamma_{r}\left(\mathrm{CH}_{2}\right)$ mode is a single band. This would be in support of the hypothesis that the splitting results from an interaction between molecules, since this interaction would diminish when neighboring chains in the unit cell are no longer equivalent. We are of course assuming (which does not seem unreasonable) that the solid solution has the same crystal structure as the normal paraffin. (2) The frequency of this single band in the solid solution is $725 \mathrm{~cm}^{-1}$, which is different from the value of $721 \mathrm{~cm}^{-1}$ for this frequency in the liquid state. This probably represents the difference between the $\gamma_{r}\left(\mathrm{CH}_{2}\right)$ frequency in the planar zig-zag chain and in the rotational isomers of it which are found in the liquid. This is analogous to our assignment of the $1353 \mathrm{~cm}^{-1}$ band to a $\gamma_{w}\left(\mathrm{CH}_{2}\right)$ mode on a chain in the disordered phase. (3) It appears that the magnitude of the splitting is a function of the concentration. While in the pure paraffin the components are at 721 and $731 \mathrm{~cm}^{-1}$, in the $1: 1$ solution they are at 722 and $728 \mathrm{~cm}^{-1}$ and in the $1: 3$ solution they occur at 724 and $727 \mathrm{~cm}^{-1}$. This is difficult to understand on the basis of an interaction only between adjacent molecules, ${ }^{43,45}$ and would seem to imply a more extended interaction between molecules in the crystal.

On the basis of a van der Waals interaction between the hydrogen atoms on adjacent molecules, an attempt has been made ${ }^{45}$ to account for the magnitude of the observed splitting at $725 \mathrm{~cm}^{-1}$ and the polarization of the components. There are two substantial discrepancies between the predictions of this theory and observation. (1) The theory predicts that the two components of the doublet should both be at a higher frequency

\footnotetext{
${ }^{45}$ R. S. Stein, J. Chem. Phys. 23, 734 (1955).
}

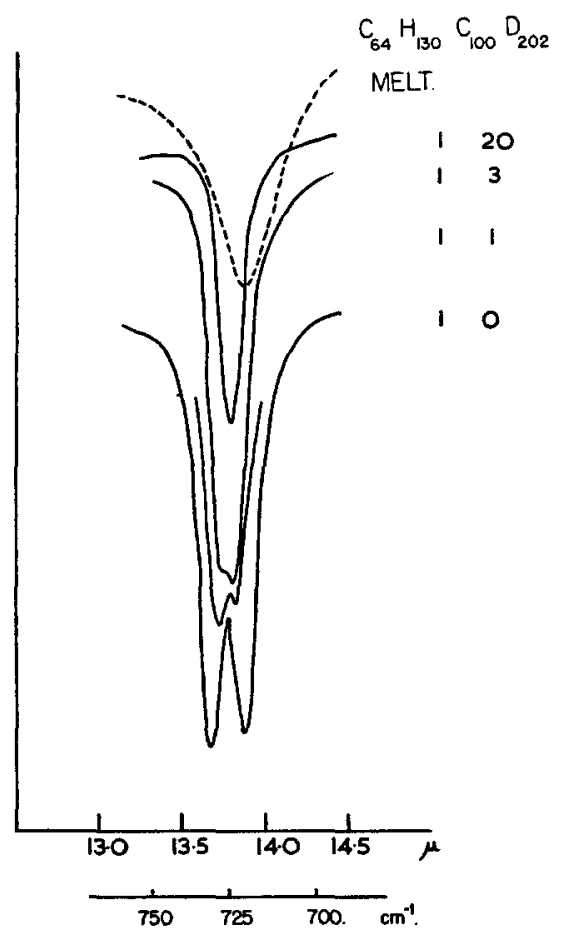

Fig. 12. Spectra of solid solutions of $\mathrm{C}_{64} \mathrm{H}_{130}$ in $\mathrm{C}_{100} \mathrm{D}_{202}$. Numbers give weight ratio.

than the mode in an isolated molecule. As we have seen from the study of the solid solutions this does not seem to be the case. The single frequency of the unperturbed molecule is between the values of the doublet in the perturbed case. There is a possibility that the value in the unperturbed molecule is nevertheless different from that in an isolated molecule, as a result of the effect of the crystalline field..$^{42}$ Usually however, the frequency in the solid is lower than in the isolated molecule. The discrepancy requires clarification. (2) A more serious difficulty is in the predicted polarization of the two components. The theory predicts that for the 721-731 $\mathrm{cm}^{-1}$ doublet the high frequency component should be polarized along the $a$-axis (as is found), while for the $\delta\left(\mathrm{CH}_{2}\right)$ mode doublet, which we find at 1461 and 1470 $\mathrm{cm}^{-1}$, the high frequency component should be polarized along the $b$-axis. This is not the case for monoclinic $\mathrm{C}_{36} \mathrm{H}_{74},{ }^{4}$ as can be seen from Fig. 13. We have recently obtained the spectrum of orthorhombic $\mathrm{C}_{29} \mathrm{H}_{60}$ and find the same situation here, i.e., both at $725 \mathrm{~cm}^{-1}$ and $1460 \mathrm{~cm}^{-1}$ the high frequency component is polarized along the $a$-axis of the crystal. It is difficult to reconcile this with the proposed theory. In fact, the progressive splitting of the $725 \mathrm{~cm}^{-1}$ band in solid solutions of a deuteroparaffin makes it difficult to believe that the interaction could be the simple one proposed between adjacent molecules.

We have also observed that in a single crystal of $\mathrm{C}_{36} \mathrm{H}_{74}$ the $\mathrm{CH}_{2}$ stretching frequencies are split, in accordance with the group theory analysis. For the $\nu_{a}\left(\mathrm{CH}_{2}\right)$ mode, the high frequency component at 2924 


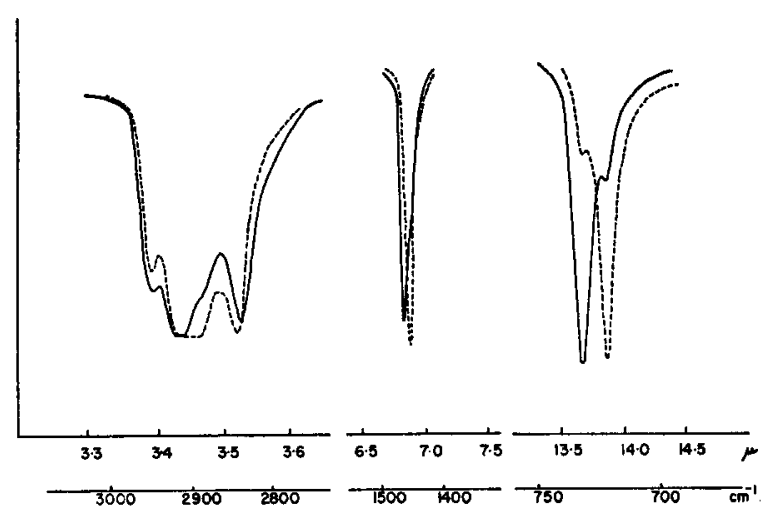

FIG. 13. Spectrum of single crystal of monoclinic $n-\mathrm{C}_{36} \mathrm{H}_{74}$. - radiation with electric vector polarized along $a$-axis, radiation with electric vector polarized along $b$-axis.

$\mathrm{cm}^{-1}$ is polarized along the $a$-axis, the low frequency component at $2899 \mathrm{~cm}^{-1}$ being polarized along the $b$-axis. For the $\nu_{s}\left(\mathrm{CH}_{2}\right)$ mode, the high frequency component at $2857 \mathrm{~cm}^{-1}$ is polarized along the $b$-axis, the low frequency component at $2850 \mathrm{~cm}^{-1}$ being polarized along the $a$-axis. This reversal of polarization of the high frequency component for $\nu_{s}\left(\mathrm{CH}_{2}\right)$ is difficult to account for on the simple interaction theory. ${ }^{45}$

We may consider now the $\gamma_{t}\left(\mathrm{CH}_{2}\right)$ mode, which is predicted to be active in crystalline polyethylene and to exhibit parallel polarization. Studies on $n$-paraffins ${ }^{41}$ have suggested that this frequency should occur at about $1300 \mathrm{~cm}^{-1}$. It should be infrared active only for the even-numbered carbon chains. In our examination of the $n$-paraffins $\mathrm{C}_{28} \mathrm{H}_{58}, \mathrm{C}_{30} \mathrm{H}_{62}, \mathrm{C}_{36} \mathrm{H}_{74}$, and $\mathrm{C}_{64} \mathrm{H}_{130}$ we find a very weak band at about $1295 \mathrm{~cm}^{-1}$ which is common to all of these spectra. It is possible that this is the $\gamma_{t}\left(\mathrm{CH}_{2}\right)$ mode of the crystalline phase. The relative intensity of this band diminishes with increasing chain length, and we would therefore expect that it is probably not observable in the spectrum of polyethylene. The only band found in this region in polyethylene is that at $1303 \mathrm{~cm}^{-1}$. As we have already seen, this band arises from the amorphous component and therefore cannot be assigned to $\gamma_{t}\left(\mathrm{CH}_{2}\right)$ in the crystal. The question arises, however, as to whether this band might be a $\gamma_{t}\left(\mathrm{CH}_{2}\right)$ mode of an amorphous chain. The evidence does not strongly favor this possibility. In the deuteroparaffin spectrum, a band of similar shape and intensity, which also increases in intensity upon melting, is found at about $975 \mathrm{~cm}^{-1}$. The ratio of frequencies, 1.34, does not seem appropriate to a pure twisting mode. In addition, the observed parallel polarization of the $1303 \mathrm{~cm}^{-1}$ band in oriented samples is not readily interpretable in terms of a $\gamma_{t}\left(\mathrm{CH}_{2}\right)$ mode. If the $\mathrm{CH}_{2}$ groups in the amorphous regions are considered as independent units of symmetry $C_{2 v}$, then a twisting mode is forbidden in the infrared. If we take a $\mathrm{CH}_{2}-\mathrm{CH}_{2}$ unit, of symmetry $C_{2 h}$, as the independent group, then a $\gamma_{t}\left(\mathrm{CH}_{2}\right)$ mode is permitted but its polarization is predicted to be perpendicular to the carbon chain axis, as in the case of the crystalline $n$-paraffins. ${ }^{41}$ It is therefore probable that if this frequency occurs in a partially oriented amorphous chain it would show perpendicular polarization. These two facts lead us to assign the 1303 $\mathrm{cm}^{-1}$ band most probably to a $\gamma_{w}\left(\mathrm{CH}_{2}\right)$ mode of an amorphous chain.

The previous discussion of the spectrum of crystalline polyethylene has been based on the assumption that the chain is infinitely long. This is, of course, not actually the case, and as a result it is expected ${ }^{19}$ that the skeletal vibrations, which are inactive for an infinite chain, can now become active. We wish to consider briefly the possible occurrence of such bands in the spectra of polyethylene and of paraffins. A calculation ${ }^{1}$ of the values of the two skeletal frequencies $A_{0}$ and $B_{10}$ of a single chain (see Fig. 3(a)) indicates that they should be found at about $1070 \mathrm{~cm}^{-1}$ and $1137 \mathrm{~cm}^{-1}$, respectively. An examination of the spectra of the various $n$-paraffins studied in this work shows a fairly uniform grouping of bands at about $1065 \mathrm{~cm}^{-1}$ and $1100 \mathrm{~cm}^{-1}$. (No such bands were found in $\mathrm{C}_{64} \mathrm{H}_{130}$, which probably indicates that this molecule is behaving very much like an infinite chain.) An example of these bands is shown in Fig. 6a, where they occur at 1068 $\mathrm{cm}^{-1}$ and $1100 \mathrm{~cm}^{-1}$. It seems probable that they are to be associated with the above-mentioned skeletal modes. This is substantiated by their behavior on melting the sample. As Fig. 6b and $\mathrm{c}$ show, they disappear and are replaced by a single stronger band at $1078 \mathrm{~cm}^{-1}$. The latter probably represents the mean value of the skeletal stretching frequency in the amorphous chains. We would therefore assign the weak band at $1080 \mathrm{~cm}^{-1}$ in polyethylene to a skeletal frequency in the amorphous phase.

As for the remaining weak bands in the spectrum of polyethylene, little can be said beyond the statement that they probably are combinations and overtones. In one case this seems to be fairly well substantiated, viz., for the band at $2010 \mathrm{~cm}^{-1}$ in polyethylene. This band is found at $2015 \mathrm{~cm}^{-1}$ in polycrystalline $\mathrm{C}_{36} \mathrm{H}_{74}$, and is very weak. Its relative intensity increases, however, when the sample is melted, much as does the 1303 $\mathrm{cm}^{-1}$ band. In fact the band at $2010 \mathrm{~cm}^{-1}$ could be a combination involving the 1303 and $721 \mathrm{~cm}^{-1}$ bands. The other cases are not so clear-cut, and may very well arise from combinations between active and inactive modes. The very weak band at $965 \mathrm{~cm}^{-1}$ in polyethylene is also found in the spectra of the $n$-paraffins, but we have been unable to assign it.

\section{ACKNOWLEDGMENTS}

Two of the authors (S.K. and C.Y.L.) wish to express their gratitude to E. I. du Pont de Nemours Co. for supporting grants, during the tenure of which this work was done.

We also wish to thank F. P. Reding of Carbide and Carbon Chemicals Company and A. E. Smith of Shell Development Company for making the samples of $n$-paraffins available to us. 